Chefornak Energy Configuration Options

\title{
Energy Infrastructure Optimization to Reduce Fuel Cost and Dependence in Chefornak, Alaska
}

\section{August 2018}

Antonio Jimenez 
NREL/TP-5000-70579

\title{
Chefornak Energy Configuration Options
}

\author{
Energy Infrastructure Optimization to Reduce Fuel Cost \\ and Dependence in Chefornak, Alaska
}

Antonio Jimenez

August 2018

This work was authored by the National Renewable Energy Laboratory, operated by Alliance for Sustainable Energy, LLC, for the U.S. Department of Energy (DOE) under Contract No. DE-AC36-08GO28308. Funding provided by the U.S. Department of Energy under the Grid Modernization Laboratory Consortium. The views expressed in the article do not necessarily represent the views of the DOE or the U.S. Government. This report is available at no cost from the National Renewable Energy Laboratory (NREL) at www.nrel.gov/publications.

DOE reports produced after 1991 and a growing number of pre-1991 documents are available free via www. OSTI.gov. 


\begin{abstract}
Power systems in rural Alaska villages face a unique combination of challenges that can increase the cost of energy and lower energy supply reliability. In the case of the remote village of Chefornak, diesel and heating fuel are shipped in by barge or flown in by aircraft. This report presents a technical analysis of several energy infrastructure upgrade and modification options to reduce the amount of fuel consumed by the community of Chefornak and reduce energy costs. Reducing fuel usage saves money and makes the village more resilient to fuel supply disruptions. The analysis considers demand-side options, such as energy efficiency, along with the installation of wind and solar power generation options. Some novel approaches are also considered, including battery energy storage and the use of electrical home heating stoves powered by renewable generation that would otherwise be spilled and wasted. This report concludes with recommendations for Chefornak based on economic factors. General conclusions are also included to support future work analyzing similar energy challenges faced by remote Arctic communities.
\end{abstract}




\section{Executive Summary}

Alaska faces unprecedented challenges in modernizing its rural energy infrastructure. Across the state, there are approximately 200 isolated microgrid systems that are not connected to larger grids, with most of these systems relying almost exclusively on imported fuel (primarily diesel) to meet electrical, space/water heating, and transportation requirements. These communities, with populations ranging from 50 to 6,000 people and comprised primarily of Alaska Natives, have some of the highest energy costs in the nation (up to $\sim 10$ times the national average).

Because of their remoteness, these microgrids are expensive to build and maintain, and the fuel imported into the communities is a high-priced commodity. It is a goal of many Alaskans to integrate renewable energy, efficiency, and storage into these microgrids, with the expectation that the new technologies will reduce a community's reliance on diesel fuel while improving reliability and resiliency. Currently about 35 communities ${ }^{1}$ have deployed a renewable system; however, there are still significant challenges to overcome. Renewable contribution levels have generally been limited (typically around 20\% on an energy basis) due to factors including lack of sophisticated switchgear and protective systems, lack of sophisticated control automation, substandard distribution systems, inadequate diesel sizing, one-off engineering designs, high storage costs, limited financial resources, and a lack of a trained workforce. Integrating variable resources into existing diesel systems, combined with fluctuating demand, can cause strain on the microgrid system if controls and hardware are not upgraded as well. Often, energy storage or demand management systems can be deployed to smooth the sometimes abrupt changes in generation or demand and provide a means for more cost effective "spinning" reserves, but this is frequently accompanied with higher initial costs and leads to more complex controls and operations and maintenance requirements.

To address this need, the U.S. Department of Energy is funding the Alaska Microgrid Partnership (AMP) through the Grid Modernization Program. AMP is a multi-stakeholder collaborative comprised of national laboratories and Alaska-based partners. The overarching goal of AMP is to reduce the use of total imported fuel into communities to secure all energy services by at least 50\% in Alaska's remote microgrids without increasing system lifecycle costs and while improving overall system reliability, security, and resilience. Another goal of AMP is to investigate if a combination of energy efficiency (EE) and high-contribution (from renewable energy [RE]) power systems can reduce total imported energy usage by $50 \%$ while lowering life cycle costs (LCCs) and improving reliability and resiliency. A technoeconomic analysis was conducted for the community of Chefornak to investigate system architectures that could meet the goal of reducing imported fuel consumption by $50 \%$ or more.

Due to the lack of information and complexity of the transportation sector, results of this effort focus on electric and thermal energy services.

Chefornak is a small community located in the Lower Yukon-Kuskokwim Region of southwest Alaska. Total population is approximately 440 individuals occupying about 90 residences. In addition, Chefornak has roughly a dozen community and commercial buildings.

Table EX-1 summarizes the energy situation at Chefornak.

\footnotetext{
${ }^{1}$ Alaska Energy Authority. 2017. Statistical Report of the Power Cost Equalization Program: Fiscal Year 2016, July 1, 2015 - June 30, 2016, Twenty-Eighth Edition. http://www.akenergyauthority.org/Portals/0/DNNGalleryPro/uploads/2017/2/28/FY16PCEstatistical.pdf.
} 
Table EX-1: Chefornak Energy Overview

\begin{tabular}{||l|l||}
\hline Diesel plant & $\begin{array}{l}\text { 2x 371-kW generators } \\
1 x \text { 179-kW generator }\end{array}$ \\
\hline Annual electricity generation (kWh) & $1,597,000$ (Avg. load: $180 \mathrm{~kW})$ \\
\hline Annual thermal consumption (kWh) & $7,905,000$ (Avg. load: $900 \mathrm{~kW})$ \\
\hline Annual diesel fuel consumption [FY 2016] (gallons) & 117,500 \\
\hline Annual heating oil consumption [FY 2016] (gallons) & 248,200 \\
\hline $\begin{array}{l}\text { Diesel fuel cost (for electricity production) [FY 2016] } \\
\text { (\$/gallon) }\end{array}$ & $\$ 4.14(2012-2016$ range: \$4.14 - \$6.65) \\
\hline Heating oil cost [FY 2016] (\$/gallon) & $\$ 4.55$ \\
\hline
\end{tabular}

The major planned project is the installation of three Frontier (F24) 100-kW wind turbines.

The modeling was conducted using the Hybrid Optimization Model for Electric Renewables (HOMER) microgrid simulation and optimization software. The analysis optimized the following items:

- $\quad$ Number of wind turbines (fixed turbine rated power of $100 \mathrm{~kW}$ )

- $\quad$ Photovoltaic (PV) capacity $\left(\mathrm{kW}_{\mathrm{DC}}\right)$

- $\quad$ Battery storage capacity (kWh)

- $\quad$ Converter capacity $(\mathrm{kW})$

- Total electric thermal stove capacity $(\mathrm{kW})$. [Note: The electric thermal stoves allow renewable energy that would otherwise be spilled to displace heating oil.]

The analysis included the following sensitivity studies:

- Discount rate (nominal): $4 \%$ and $8 \%$ (with $1 \%$ inflation $\rightarrow 3 \%$ and $7 \%$ real)

- EE: no EE implementation, EE implementation (5\% electrical consumption and 25\% reduction in thermal consumption (total implementation cost \$2,250,000).

Table EX-2 summarizes the key modeling assumptions. 
Table EX-2: Key Modeling Assumptions

\begin{tabular}{||l|l|l||}
\hline \multicolumn{1}{|c|}{ Item } & \multicolumn{1}{|c||}{ Value } & \multicolumn{1}{c||}{ Note } \\
\hline $\begin{array}{l}\text { Annual electricity consumption } \\
(\mathrm{kWh})\end{array}$ & $\begin{array}{l}\text { 1,790,000 (no EE) (Avg. } \\
\text { load: } 205 \mathrm{~kW})\end{array}$ & $\begin{array}{l}\text { Consumption extrapolated to } \\
\text { late 2020s }\end{array}$ \\
\hline Annual thermal consumption (kWh) & $\begin{array}{l}\text { 8,596,000 (no EE) (Avg. } \\
\text { load: } 980 \mathrm{kWth})\end{array}$ & $\begin{array}{l}\text { Consumption extrapolated to } \\
\text { late 2020s }\end{array}$ \\
\hline $\begin{array}{l}\text { Diesel fuel cost (for electricity } \\
\text { production) (\$/gallon) }\end{array}$ & $\$ 4.50 /$ gallon & $\begin{array}{l}5 \% \text { reduction in electricity } \\
\text { consumption }\end{array}$ \\
\hline Heating oil cost (\$/gallon) & $\$ 5.00 /$ gallon & $\begin{array}{l}25 \% \text { reduction in thermal } \\
\text { consumption }\end{array}$ \\
\hline EE (electrical) & $\begin{array}{l}\$ 1.15 \text { per annual } \mathrm{kWh} \\
\text { saved }\end{array}$ & $\begin{array}{l}\$ 1.00 \text { per annual } \mathrm{kWh} \\
\text { saved }\end{array}$ \\
\hline EE (thermal) & & \\
\hline
\end{tabular}

Based on the assumptions detailed in this report, Table EX-3 and Table EX-4 show the recommended (based on lowest net present cost [NPC]) system configurations for low and high discount rate scenarios. In all cases, the RE retrofits should be paired with EE upgrades.

Table EX-3: Recommended System Configuration (Low Discount Rate Case with EE)

\begin{tabular}{|c|c|c|}
\hline Component & Value & Note \\
\hline Large diesel size (kW) & $371 \mathrm{~kW}$ & Keep current diesel generator \\
\hline Small diesel size (kW) & $179 \mathrm{~kW}$ & Keep current diesel generator \\
\hline $\begin{array}{l}\text { \# wind turbines } \\
\text { (Frontier 24) } \\
\text { (100 kW/turbine) }\end{array}$ & 8 & $\begin{array}{l}\text { \# of turbine can range from } 5 \text { to } 10 \text { with little } \\
\text { change in cost }\end{array}$ \\
\hline PV capacity $\left(k W_{D C}\right)$ & 0 & \\
\hline Converter size $(\mathbf{k W})$ & $200 \mathrm{~kW}$ & $\begin{array}{l}\text { Capacity can range from } 150 \mathrm{~kW} \text { to } 300 \mathrm{~kW} \text { with } \\
\text { little change in cost. In practice, it may make the } \\
\text { most sense to size the converter to meet the peak } \\
\text { load }\end{array}$ \\
\hline Battery bank size (kWh) & $300 \mathrm{kWh}$ & $\begin{array}{l}\text { Capacity can range from } 100 \mathrm{kWh} \text { to } 600 \mathrm{kWh} \\
\text { with little change in cost }\end{array}$ \\
\hline $\begin{array}{l}\text { Electric thermal stove } \\
\text { capacity }(\mathrm{kW})\end{array}$ & $650 \mathrm{~kW}$ & Probably a low estimate \\
\hline
\end{tabular}


Table EX-4: Recommended System Configuration (High Discount Rate Case with EE)

\begin{tabular}{|c|c|c|}
\hline Component & Value & Note \\
\hline Large diesel size (kW) & $371 \mathrm{~kW}$ & Keep current diesel generator \\
\hline Small diesel size (kW) & $179 \mathrm{~kW}$ & Keep current diesel generator \\
\hline $\begin{array}{l}\text { \# wind turbines } \\
\text { (Frontier 24) (F24) } \\
\text { (100 kW turbine) }\end{array}$ & 5 & $\begin{array}{l}\text { \# of turbine can range from } 3 \text { to } 6 \text { with little } \\
\text { change in cost }\end{array}$ \\
\hline PV capacity $\left(\mathbf{k} W_{D C}\right)$ & 0 & \\
\hline Converter size (kW) & $200 \mathrm{~kW}$ & $\begin{array}{l}\text { Capacity can range from } 150 \mathrm{~kW} \text { to } 250 \mathrm{~kW} \text { with } \\
\text { little change in cost }\end{array}$ \\
\hline Battery bank size (kWh) & $300 \mathrm{kWh}$ & $\begin{array}{l}\text { Capacity can range from } 100 \mathrm{kWh} \text { to } 600 \mathrm{kWh} \\
\text { with little change in cost }\end{array}$ \\
\hline $\begin{array}{l}\text { Electric thermal stove } \\
\text { capacity }(\mathbf{k W})\end{array}$ & $400 \mathrm{~kW}$ & Probably a low estimate \\
\hline
\end{tabular}

There are plans to install three F24 wind turbines in Chefornak within the next year. The analysis indicates that, depending on the discount, the installation should include additional wind turbines, roughly $300 \mathrm{kWh}$ of battery storage, roughly $200 \mathrm{~kW}$ of converter capacity, $400 \mathrm{~kW}$ to $650 \mathrm{~kW}$ of electric thermal stove capacity, and the integration and controls needed to allow for diesel-off operation. The installation of this equipment should be combined with aggressive EE implementation.

Overall modeling results are summarized in Figure EX-1 and Figure EX-2. Figure EX-1 shows the battery storage size, converter rating, and electric thermal stove capacity as a function of the number of wind turbines in the system. Note that the respective component sizes are for the lowest NPC system with the given number of wind turbines. PV was never selected as part of a lowest NPC configuration.

Figure EX-2 shows NPC (left axis) and fuel consumption (right axis) versus number of wind turbines (for the configurations shown in Figure EX-1). The results are for the lowest cost configuration (under the low discount rate scenario) featuring the given number of wind turbines. The results are for the low discount rate scenario. The blue line shows how the NPC changes with the number of wind turbines. Under the low discount rate scenario, the lowest NPC system has eight wind turbines. One thing to note is the flatness of the NPC curve. One important item to note is that (for this analysis) the cost curve in the vicinity of the optimum is quite shallow with respect to number of wind turbines, converter capacity, and battery capacity. Thus, the component number/size can vary moderately from the values shown in the tables with little change in NPC. For example, the number of wind turbines can vary from 5 to 10 with little change in the NPC.

This flatness of the cost curve means that there is flexibility to tailor a configuration to accommodate considerations other than NPC. For example, concerns about wind turbine technology risk or limited available capital funds would lead to a configuration with fewer wind turbines. A belief that fuel prices will be higher than assumed in the analysis may lead to a configuration with more wind turbines.

The red line shows total fuel consumption (for power generation and heat) as a function of the number of wind turbines in the system. The results are for the low discount rate scenario. 


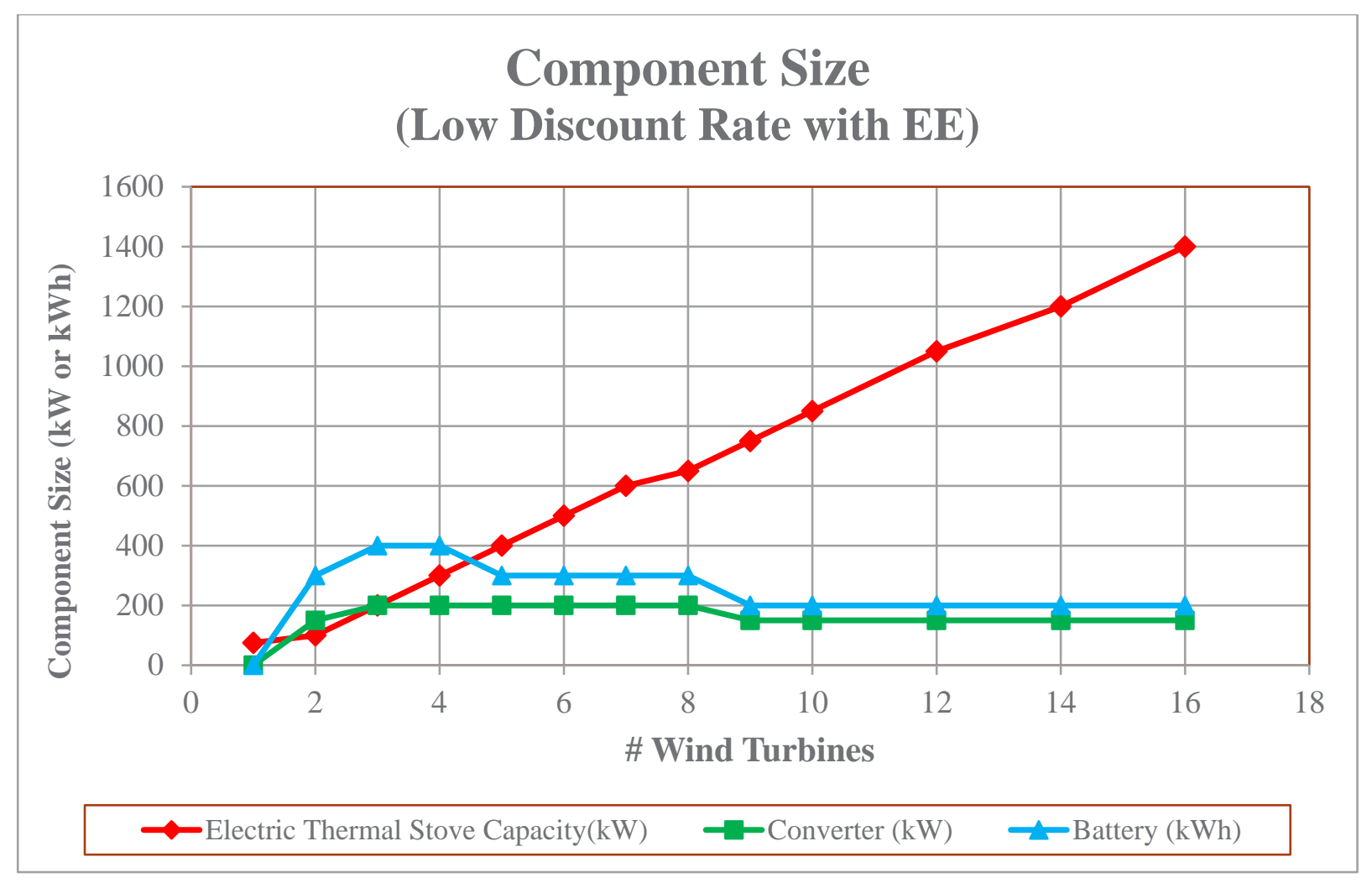

Figure EX-1: Component size versus number of $(100-\mathrm{kW})$ wind turbines

Figure EX-2 also shows the effect of EE. The blue triangle and red star on the upper left of the chart show the NPC and fuel consumption, respectively, of the configuration with zero wind turbines and with no EE implementation (i.e., the business as usual case). As can be seen, EE implementation alone reduces the NPC by $\$ 3$ million and reduces annual fuel consumption by more than 70,000 gallons/year.

Implementation of the EE measures alone, with a capital cost of \$2.25 million, reduces fuel consumption by almost 73,000 gallons/year. Achieving the same reduction with RE alone requires a system with four wind turbines with an initial capital cost of $\$ 3.45$ million.

Another way to examine the value of EE is to study what is needed to achieve a $50 \%$ reduction in fuel consumption. The "base case" fuel consumption (zero wind turbines and no EE) is 373,000 gallons/year. Without EE, a system with 14 wind turbines, requiring a capital investment of \$14 million, is needed to reduce overall fuel consumption by $50 \%$. With the assumed EE measures, a system with only seven turbines, with a capital cost of \$7.5 million (for both the RE and the EE), is required to achieve the same fuel reduction.

With a good wind resource (based on onsite measurements, the estimated average wind speed at Chefornak is $7.4 \mathrm{~m} / \mathrm{s}$ at 29 meters above ground level) and wind turbines that are more cost effective (for their size) than what has been customarily deployed in remote Alaska, achieving a 50\% reduction in imported fuel (for electricity and heat) may be economically feasible with a combination of RE retrofits and EE. Achieving 50\% imported fuel reduction with RE alone is generally economically marginal at best. 


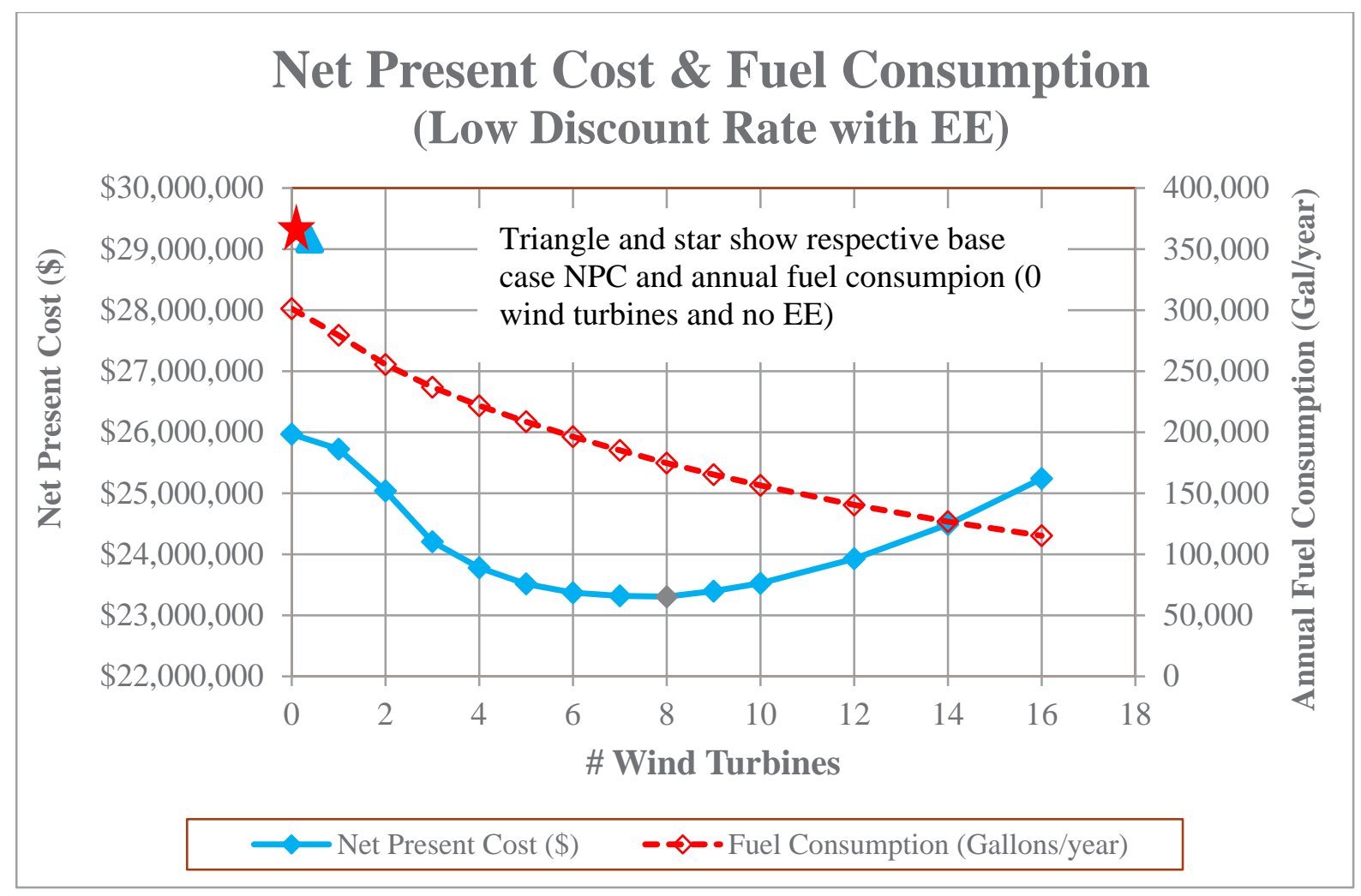

Figure EX-2: Net present cost and fuel consumption versus number of wind turbines

EE is key to achieving greater imported fuel reduction. The data indicate that the implementation of cost effective EE measures alone (mostly weatherization in the case of remote Alaska communities) can reduce imported fuel consumption by $20 \%$ or more. .,3,4,5,6,7 $^{2}$

The conversion efficiency of diesel fuel to electricity is significantly lower than that to heat due to the relative conversion efficiencies of diesel generators and fuel-burning stoves. Thus, generating a kilowatthour of electricity requires more fossil fuel than generating a kilowatt-hour of heat, and energy from electricity-producing RE technologies, such as wind or PV, are more cost competitive versus dieselgenerated electricity than versus heating oil-generated space heat or hot water. This also partially explains why the initial wind turbines, which mostly displace diesel-generated electricity, displace more fuel than do successive wind turbines as a larger proportion of the energy production from each successive turbine is used to meet the heating load.

\footnotetext{
${ }^{2}$ AEA. Remote Alaska Communities Energy Efficiency Competition: Phase II Summary and Strategic Energy Efficiency Plan-Chefornak. 2016 Aug 19

${ }^{3}$ Dennis Meiners, private communication, 28 Dec 2016

${ }^{4}$ Alaska Affordable Energy Model. http://modelresults.akenergyinventory.org/m0.24.6_d0.24.0/Chefornak/residential_energy_efficiency.html. Accessed 28 May 2017

${ }^{5}$ Alaska Affordable Energy Model. http://model-results.akenergyinventory.org/m0.24.6_d0.24.0/Chefornak/nonresidential_energy_efficiency.html. Accessed 28 May 2017

6 “AK Regional Wx Stats.xlsx" Spreadsheet provided by Neil McMahon of the Alaska Energy Authority. Data in the spreadsheet are from the Alaska Housing Financing Corporation

7 “AK Residential Wx Model Data.xlsx" Spreadsheet provided by Neil McMahon of the Alaska Energy Authority. Data in the spreadsheet are from the Alaska Housing Financing Corporation
} 
Water and space heating are an excellent use for excess wind energy that would otherwise be spilled and can allow for larger RE systems and better economics. This is what allows for the use of modestly sized converters and battery banks. Economically, use of excess wind energy for heat is needed to go beyond low-contribution wind systems.

The main value of storage is to allow for more extended diesel-off operation by covering short-term lulls in wind energy production or spikes in electricity demand. This differs from very small systems (e.g., a single house) where the storage supplies the load when there is no RE production; the value of storage for community-size systems is to allow diesel off operation when there is RE production. This function requires only a modest amount of storage (assumed to be lithium-ion batteries or a different technology with similar characteristics and competitive cost) and converter capacity. Assuming "generic" (lithiumion) batteries, the required battery bank should be sized to meet roughly an hour of average load. This provides both the energy storage needed to allow the system to bridge short-term lulls in the RE resource and the discharge capacity needed to meet spinning reserve requirements. The economically optimum converter rated power is somewhere between the average and the peak load (for situations in which the wind turbine is connected to the AC bus), as shown in Figure EX-1. In practice it may make the most sense to size the converter to meet the peak load. This adds little to the overall system NPC and allows for the battery bank to cover the load if there is a sudden loss of generation from the RE system or the diesel generators.

The analysis results are most generalizable to wind-diesel systems in communities with a good wind resource and a large thermal load. The results may not apply to the integration of other RE technologies. 


\section{Acknowledgments}

The author gratefully acknowledges the significant contributions and support of the organizations involved in the Grid Modernization Laboratory Consortium Alaska Microgrid Partnership (AMP), including the Alaska Center for Energy and Power, Intelligent Energy Systems, the Renewable Energy Alaska Project, the Alaska Energy Authority, Sandia National Laboratories, the Pacific Northwest National Laboratory (PNNL), and Lawrence Berkeley National Laboratory.

Dennis Meiners (Intelligent Energy Systems) provided extensive information and data about the community of Chefornak, as well as component cost data, without which the analysis could not have been conducted. Mark Mueller-Stoffels (formerly of the Alaska Center for Energy and Power) provided additional valuable cost data. In addition to providing information on diesel capital and operations and maintenance costs, Bill Stamm (Alaska Village Electric Cooperative) provided valuable perspective on the multiple considerations that drive utility diesel generator selection and purchase. Neil McMahon (Alaska Energy Authority) shared weatherization cost and performance data that provided a basis for estimating the cost effectiveness of energy efficiency. David Rosewater and John Eddy (Sandia National Laboratories) provided valuable feedback while conducting a concurrent analysis on the village of Shungnak, Alaska. Trevor Hardy (PNNL), Mark Weimar (PNNL), Mark Mueller-Stoffels (formerly of the Alaska Center for Energy and Power), Dennis Meiners, and Ian Baring-Gould (National Renewable Energy Laboratory) provided helpful and extensive technical feedback and critique throughout the analysis.

David Rosewater, John Eddy, Trevor Hardy, Mark Weimar, Mark Mueller-Stoffels, and Ian BaringGould reviewed the report. They provided insightful and valuable feedback that greatly improved this final version.

AMP and this author thank the U.S. Department of Energy for funding this work. In particular, the AMP team is grateful to Dan Ton (U.S. Department of Energy, Office of Electricity Delivery and Energy Reliability), John Grosh (Lawrence Livermore National Laboratory), Carl Imhoff (PNNL), Bryan Hannegan (formerly of the National Renewable Energy Laboratory), and Juan Torres (National Renewable Energy Laboratory) for their support, leadership, and assistance with the work. 



\section{Acronyms and Abbreviations}

$\begin{array}{ll}\text { AC } & \text { alternating current } \\ \text { ACEP } & \text { Alaska Center for Energy and Power } \\ \text { AEA } & \text { Alaska Energy Authority } \\ \text { AMP } & \text { Alaska Microgrid Partnership } \\ \text { DC } & \text { direct current } \\ \text { DR } & \text { discount rate } \\ \text { EE } & \text { energy efficiency } \\ \text { FY } & \text { Fiscal Year } \\ \text { HOMER } & \text { Hybrid Optimization Model for Electric Renewables } \\ \text { kW } & \text { kilowatt } \\ \text { kW } & \text { kilowatt DC } \\ \text { kW } & \text { kilowatt electric } \\ \text { kWh } & \text { kilowatt-hour } \\ \text { kW } & \text { kilowatt thermal } \\ \text { L } & \text { liter } \\ \text { LCC } & \text { life cycle cost } \\ \text { NPC } & \text { net present cost } \\ \text { O\&M } & \text { operations \& maintenance } \\ \text { PNNL } & \text { Pacific Northwest National Laboratory } \\ \text { PV } & \text { photovoltaic } \\ \text { RE } & \text { renewable energy }\end{array}$





\section{Contents}

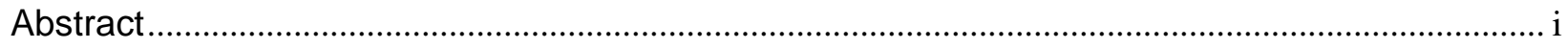

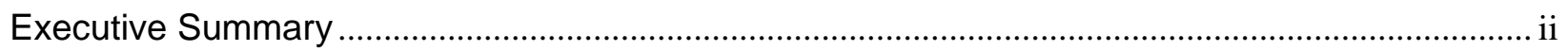

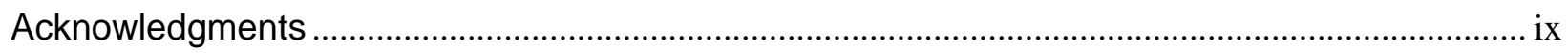

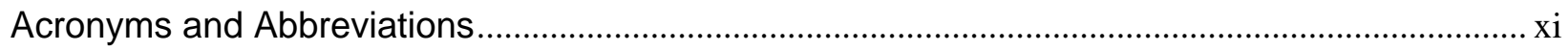

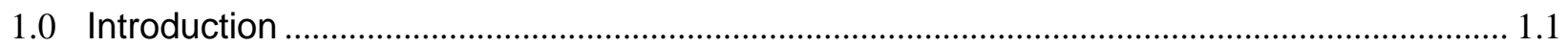

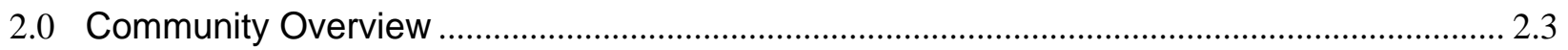

3.0 Community Electricity and Heating Infrastructure ................................................................ 3.6

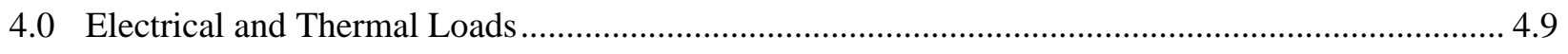

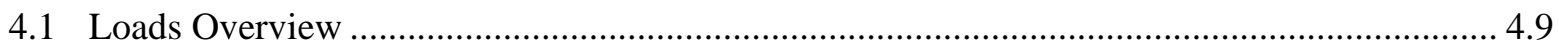

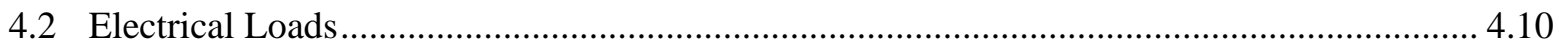

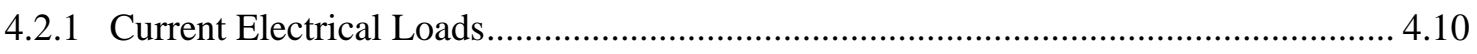

4.2.2 Future Electrical Load (Modeling Assumptions) ................................................... 4.12

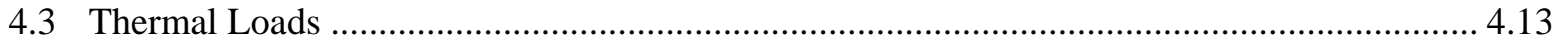

4.3.1 Current Thermal Load ............................................................................................ 4.13

4.3.2 Future Thermal Load (Modeling Assumptions)......................................................... 4.14

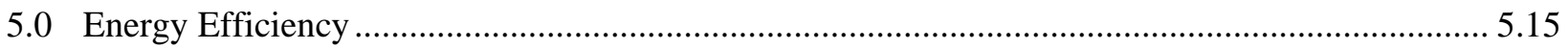

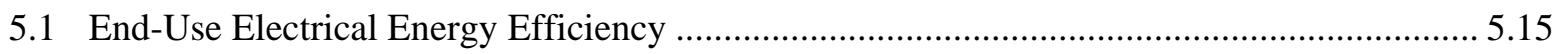

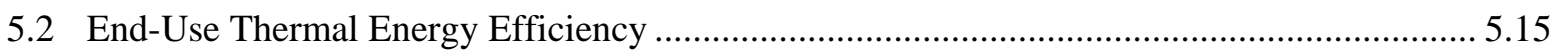

5.3 Energy Efficiency Sensitivity Analysis............................................................................ 5.16

5.4 Reduction in Electrical System Distribution Line Losses................................................... 5.16

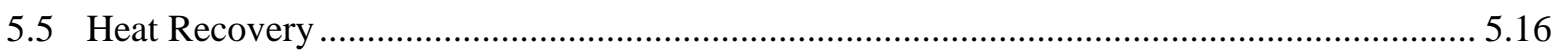

5.6 Use of Excess Renewable Energy Electricity to Meet Thermal Loads (Modeling Assumption)

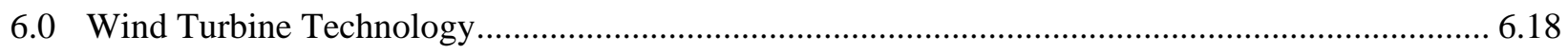

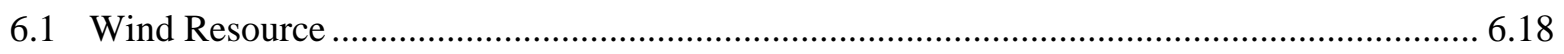

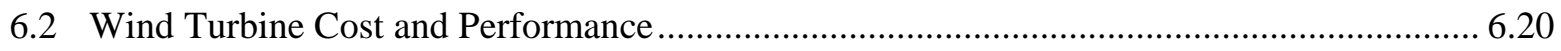

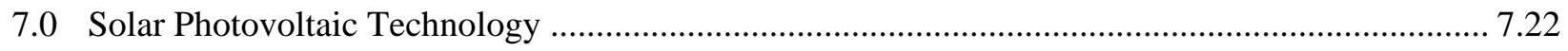

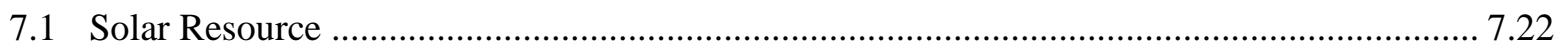

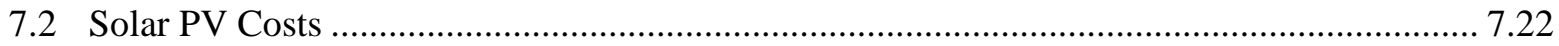

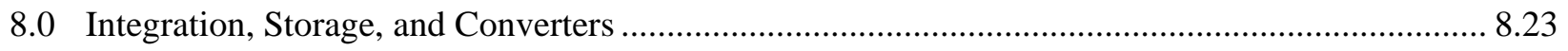

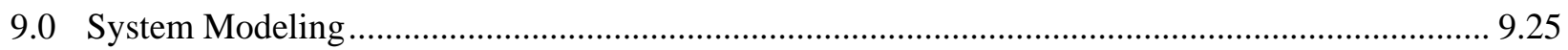

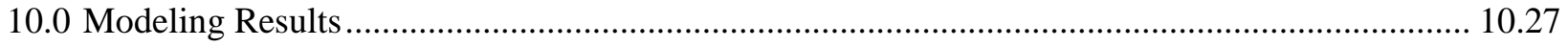

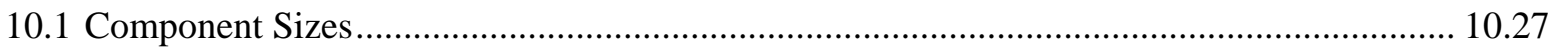

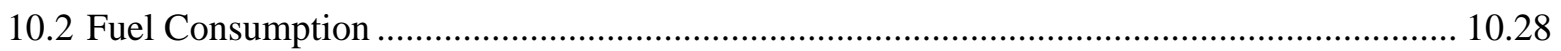

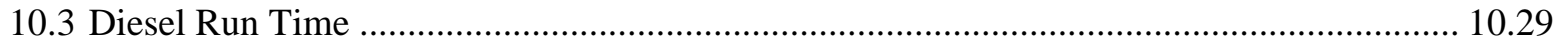

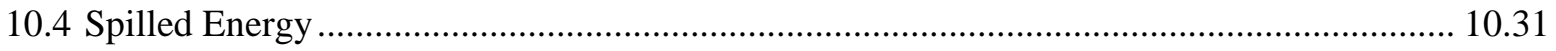

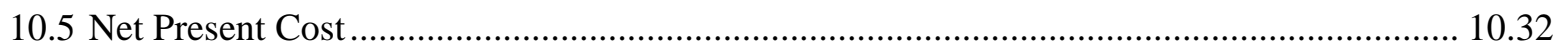




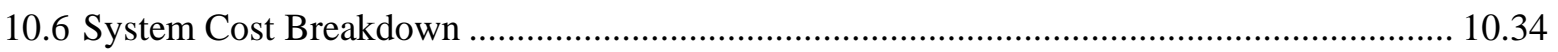

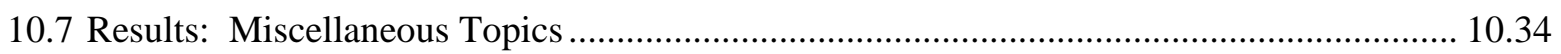

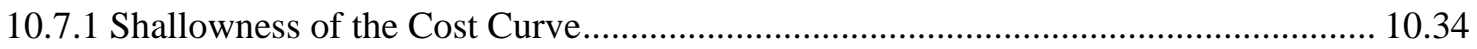

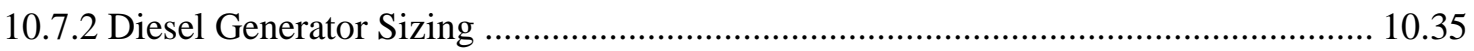

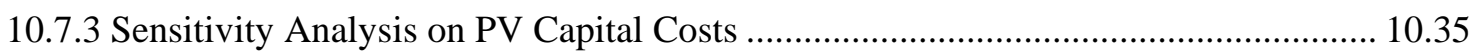

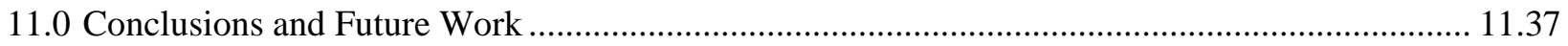

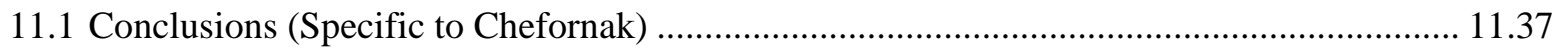

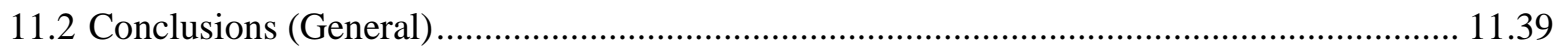

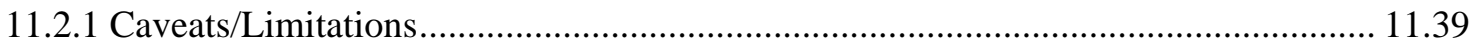

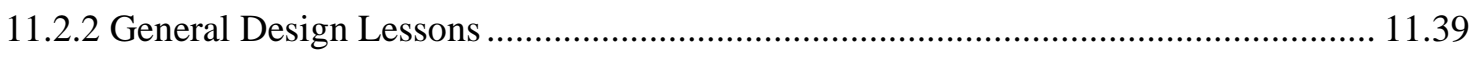

Appendix A - Analysis Inputs and Assumptions ..................................................................... A.41 


\section{Figures}

Figure EX-1: Component size versus number of (100-kW) wind turbines ............................................... vi

Figure EX-2: Net present cost and fuel consumption versus number of wind turbines..............................vii

Figure 2-1: Regional map of southwest Alaska. Source: Google Maps ................................................. 2.4

Figure 2-2: Area map of Chefornak. Source: Google Maps .................................................................. 2.5

Figure 2-3: Aerial view of Chefornak. Source: Dennis Meiners ............................................................ 2.5

Figure 4-1: End use energy consumption. Source: Alaska Energy Authority; Remote Alaska Communities Energy Efficiency Competition: Phase II Summary and Strategic Energy Efficiency Plan Chefornak; 2016 Aug 19

Figure 4-2: Fuel consumption by category. Source: Alaska Energy Authority; Remote Alaska Communities Energy Efficiency Competition: Phase II Summary and Strategic Energy Efficiency Plan - Chefornak; 2016 Aug 19

Figure 4-3: Chefornak electrical load (2015). Source: Time series data provided by Dennis Meiners... 4.10 Figure 4-4: Chefornak electrical load (2015) box plot. Source: Time series data provided by Dennis Meiners

Figure 4-5: Chefornak electrical load (2015) monthly diurnal profiles. Source: Time series data provided by Dennis Meiners

Figure 4-6: Chefornak electrical load (2015) histogram. Source: Time series data provided by Dennis Meiners

Figure 4-7: Chefornak electricity generation and consumption. Source: Alaska Energy Authority; FY 2012 - FY2016 Annual PCE Statistical Reports by Community. http://www.akenergyauthority.org/Programs/PCE

Figure 4-8: Chefornak thermal load (2015). Source: Time series data file created by Jesse Dean (NREL) 4.14

Figure 6-1: Chefornak wind data summary (6 June 2012 - 8 July 2013). Source: Based on data provided by Dennis Meiners

Figure 6-2: Preliminary Frontier F24 power curve. Source: Dennis Meiners (Intelligent Energy Systems) 6.20

Figure 7-1: Chefornak solar resource. Source: NASA Surface Meteorology and Solar Energy database 7.22

Figure 10-1: Component size versus number of wind turbines

Figure 10-2: Fuel consumption versus number of wind turbines

Figure 10-3: Diesel run time versus number of wind turbines. 10.30

Figure 10-4: Spilled energy versus number of wind turbines 10.31

Figure 10-5: Net present cost versus number of wind turbines

Figure 10-6: Cost breakdown for lowest net present cost configuration. Listed costs are annualized. . 10.34 


\section{Tables}

Table EX-1: Chefornak Energy Overview............................................................................................ii

Table EX-2: Key Modeling Assumptions........................................................................................ iv

Table EX-3: Recommended System Configuration (Low Discount Rate Case with EE) ......................... iv

Table EX-4: Recommended System Configuration (High Discount Rate Case with EE)........................... v

Table 2-1: Chefornak Overview. Source: State of Alaska Department of Commerce, Community, and Economic Development website, https://www.commerce.alaska.gov/dcra/DCRAExternal/community/Details/9ac24aaf-73bd-45f6a5cd-be30f687c04d. Accessed 2017 May 24 ................................................................................ 2.3

Table 3-1: Chefornak Generator Data. Source: Alaska Energy Authority; Village Power System Inventory (Inventory Conducted 2012 October 12) ......................................................................................... 3.6

Table 3-2: Diesel Generator Cost and Performance Assumptions......................................................... 3.6

Table 3-3: Chefornak Diesel Fuel Consumption and Cost (FY 2012 - FY 2016). Source: Alaska Energy Authority; FY 2012 - FY2016 Annual PCE Statistical Reports by Community. http://www.akenergyauthority.org/Programs/PCE

Table 6-1: Frontier F24 estimated costs. Source for capital cost: Dennis Meiner (Intelligent Energy Systems), Alaska Center for Energy and Power. Source O\&M costs: Vandermeer, J., MuellerStoffels, M., and Whitney, E., An Alaska Case Study: Wind Power Technology. JRSE, submitted. 6.21

Table 8-1: Converter and Battery Cost Curves. Source: conversations with installers, Vandermeer, J., Mueller-Stoffels, M., and Whitney, E. An Alaska Case Study: Energy Storage Technologies. JRSE, submitted.

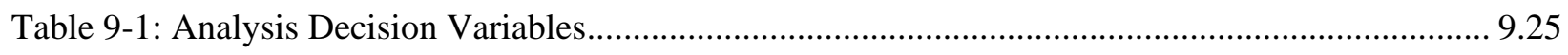

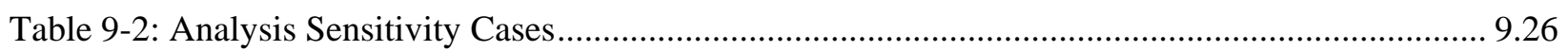

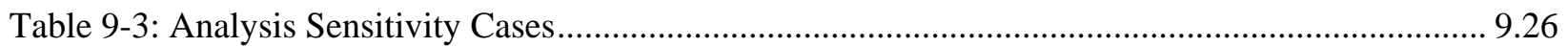

Table 10-1: Details for Selected Configurations........................................................................... 10.33

Table 10-2: *Percent Change in Net Present Cost Versus Converter and Battery Bank Size ............... 10.35

Table 10-3: *System Configuration Versus PV Capital Cost ........................................................... 10.36

Table 11-1: Recommended System Configuration (Low Discount Rate Case with Energy Efficiency) 11.37

Table 11-2: Recommended System Configuration (High Discount Rate Case with Energy Efficiency) 11.38 


\subsection{Introduction}

Alaska — perhaps more than any other region in the country-faces unprecedented challenges in modernizing its rural energy infrastructure. Across the state, there are approximately $200^{8}$ isolated microgrid systems that are not connected to larger grids, with most of these systems relying almost exclusively on imported fuel (primarily diesel) to meet electrical, space/water heating, and transportation requirements. These communities, with populations ranging from 50 to 6,000 people and comprised primarily of Alaska Natives, have some of the highest energy costs in the nation (up to 10 times the national average).

Because of their remoteness, microgrids are expensive to build and maintain, and the fuel imported into the communities is a high-priced commodity. It is a goal of many Alaskans to integrate renewable energy, efficiency, and storage into these microgrids, with the expectation that the new technologies will reduce a community's reliance on diesel fuel while improving reliability and resiliency. Currently about 40 communities have deployed a renewable system; however, there are still significant challenges to overcome. Renewable contribution levels have generally been limited (typically around 20\%) due to a number of factors, including system complexity, substandard distribution systems, inadequate diesel sizing, one-off engineering designs, high storage costs, limited financial resources, and a lack of a trained workforce. Integrating variable resources into existing diesel systems, combined with fluctuating demand, can cause strain on the microgrid system if controls and hardware are not upgraded as well. Often, energy storage or demand management systems can be deployed to smooth the sometimes abrupt changes in generation or demand, but this is frequently accompanied with higher initial costs and leads to more complex operations and maintenance requirements.

To address this need, the U.S. Department of Energy is funding the Alaska Microgrid Partnership (AMP) through the Grid Modernization Program. AMP is a multi-stakeholder collaborative comprised of national laboratories and Alaska-based partners. The overarching goal of AMP is to reduce diesel fuel consumption by at least $50 \%$ in Alaska's remote microgrids without increasing system lifecycle costs and while improving overall system reliability, security, and resilience. Another goal of AMP is to demonstrate that high renewable energy (RE)/storage/energy efficiency (EE) is possible and affordable, reducing total fuel usage by $50 \%$ while lowering life cycle cost and improving reliability and resiliency. This paper describes a techno-economic analysis conducted for the community of Chefornak to investigate system architectures that could meet this goal of reducing imported fuel consumption by $50 \%$ or more. A similar analysis was conducted by Sandia National Laboratories for the community of Shungnak. The results of these modeling efforts will be used by staff at the Pacific Northwest National Laboratory to investigate the feasibility of attracting private sector funding for renewable energy retrofit implementation.

This report is organized as follows:

- Chapter 2 provides an overview of Chefornak.

\footnotetext{
${ }^{8}$ Alaska Energy Authority. 2017. Statistical Report of the Power Cost Equalization Program: Fiscal Year 2016, July 1, 2015 - June 30, 2016, Twenty-Eighth Edition. http://www.akenergyauthority.org/Portals/0/DNNGalleryPro/uploads/2017/2/28/FY16PCEstatistical.pdf . Lists 191 communities participating in the Power Cost Equalization program (per the foreword on the second page of the document)
} 
- Chapter 3 provides an overview of the current power plant, including information on the diesel generators, historical energy generation data, and historical diesel fuel consumption and cost data. Also provided is current heating oil consumption and cost information.

- Chapter 4 provides the community's current and projected electrical and thermal consumption.

- Chapter 5 describes potential energy efficiency options available to the community. This chapter also provides an analysis of high-level cost and effectiveness of energy efficiency implementation.

- Chapter 6 discusses the wind resource at the community and the anticipated wind turbine cost and performance.

- Chapter 7 covers solar cost, performance, and the solar resource.

- Chapter 8 covers cost and performance of the converter, storage, and integration equipment.

- Chapter 9 discusses system modeling issues.

- Chapter 10 describes the analysis results, focusing on net present cost, fuel consumption, and diesel run time.

- Chapter 11 summarizes the high-level conclusions to be drawn from the analysis.

Although the analysis is Alaska-specific, the AMP team anticipates that the analysis results will yield insights applicable to thousands of isolated microgrid communities worldwide. In addition, the International Energy Agency estimates that $70 \%$ of the 1.1 billion people living in rural areas who presently do not have electricity could be served most cost-effectively by deploying mini-grids or isolated microgrids. ${ }^{9}$

\footnotetext{
${ }^{9}$ See International Energy Agency, World Energy Outlook 2012, pages 533 and 539. Accessed on September 25, 2015. http://www.iea.org/publications/freepublications/publication/world-energy-outlook-2012.html
} 


\subsection{Community Overview}

Chefornak is a small, remote community in southwest Alaska on the south bank of the Kania River roughly 10 miles upstream from where the latter empties into the Bering Sea. Chefornak is located 500 miles southwest of Anchorage and 100 miles southwest of the regional hub of Bethel and can only be reached by sea (fuel and general cargo barges) during the summer months, by snow machine during the winter months, and by small aircraft in all seasons. No roads, transmission grids, or pipelines connect Chefornak with larger infrastructure. Figures 2-1, 2-2, and 2-3 provide maps and an aerial view of the community. Table 2-1 provides basic community information.

Table 2-1: Chefornak Overview. Source: State of Alaska Department of Commerce, Community, and Economic Development website, https://www.commerce.alaska.gov/dcra/DCRAExternal/community/Details/9ac24aaf-73bd-45f6-a5cdbe30f687c04d. Accessed 2017 May 24

\begin{tabular}{||l|l||}
\hline \multirow{3}{*}{ Current population } & $442: 2016$ Dept. of Labor Estimate \\
& $\begin{array}{l}418: 2010 \text { Census } \\
394: 2000 \text { Census } \\
320: 1990 \text { Census }\end{array}$ \\
\hline Incorporation type & $2^{\text {nd }}$ Class City \\
\hline Borough & Bethel \\
\hline Energy region & Lower Yukon-Kuskokwim \\
\hline Regional Native Corporation & Calista Corporation \\
\hline Village Corporation & Chefarnmute, Incorporated \\
\hline Latitude & 60.1576 \\
\hline Longitude & -164.2825 \\
\hline Elevation & 1 m (3 feet) \\
\hline Electrical utility & Naterkaq Light Plant \\
\hline \# housing units & 99 total, 92 occupied \\
\hline \hline
\end{tabular}

Chefornak is located in the Lower Yukon-Kuskokwim Region. The local topography is tundra. The community is located within the western transitional climate zone, characterized by long, cold winters and short, warmer summers. ${ }^{10}$ Depending on the source, the average heating degree days range from 12,000 to $13,000 .{ }^{11,12}$ The community’s population has grown since 1990 at an average rate of $1.2 \%$ annually. This

\footnotetext{
${ }^{10}$ State of Alaska Department of Commerce, Community, and Economic Development website, https://www.commerce.alaska.gov/dcra/DCRAExternal/community/Details/9ac24aaf-73bd-45f6-a5cdbe30f687c04d Accessed 2017 May 24

${ }^{11}$ The Bethel TMY3 file used in this analysis has 12,039 HDD (Dean, Jesse. Private Communication. 3 Nov 2017

${ }^{12}$ Data from NOAA shows 13,098 HDD (http://biorealis.com/wwwroot/akclimo1.html Accessed 3 Nov 2017)
} 
is in line with regional population growth, which averages $1.5 \%$ annually. ${ }^{13}$ Economic activity is comprised mainly of subsistence hunting/gathering and some commercial fishing. ${ }^{14}$

Chefornak has approximately 80 to 90 occupied residences. The largest facility in the community is the school. Other commercial or community buildings include two stores, the town hall/bingo hall, the old school building, post office, power plant, and church. A new 2,500 sq. ft. washeteria is (at the time of this writing) under construction. A detailed survey conducted in 2016 indicates that, in general, the residences require weatherization. ${ }^{15}$

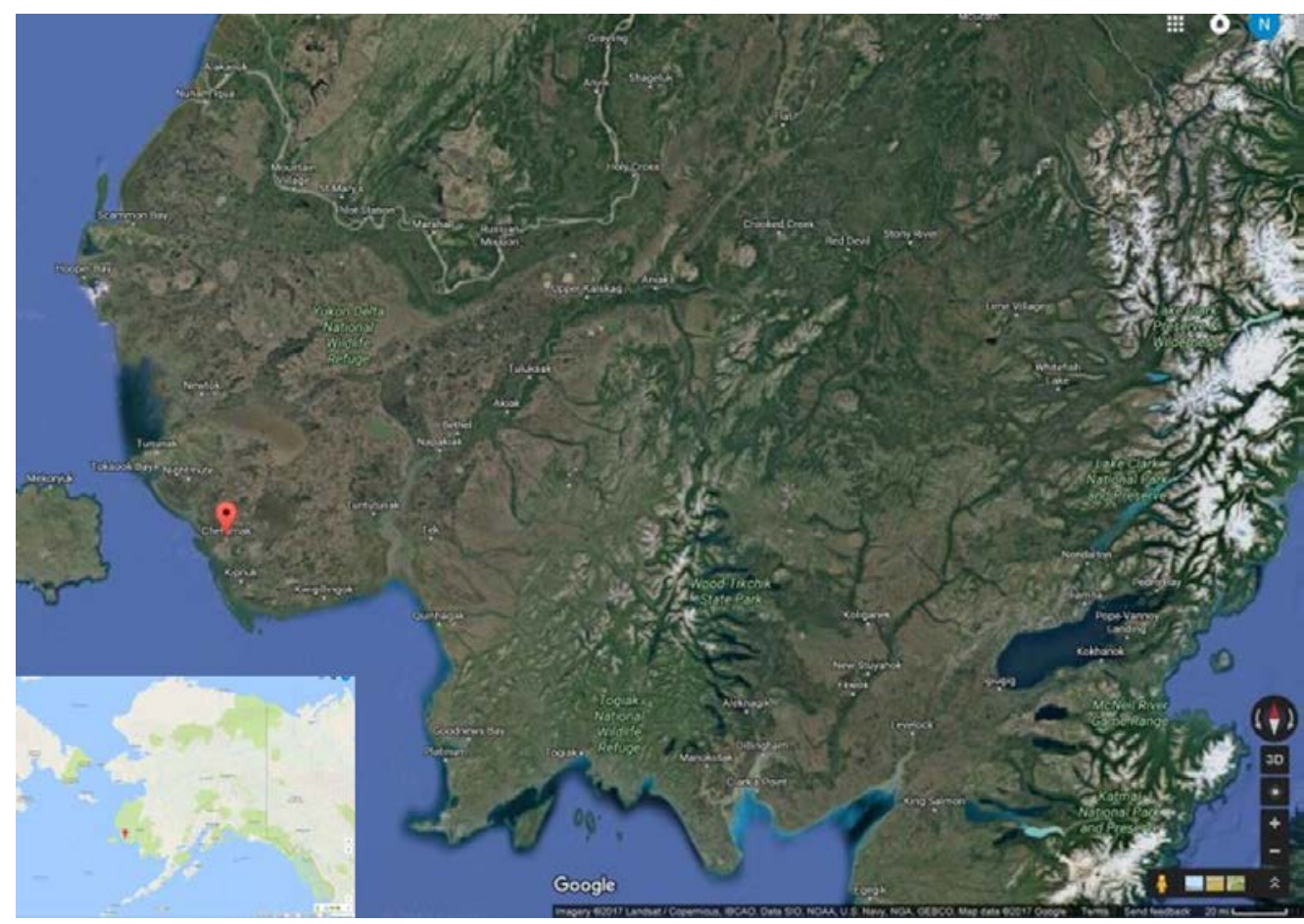

Figure 2-1: Regional map of southwest Alaska. Source: Google Maps

\footnotetext{
${ }^{13}$ Nuvista. Yukon-Kuskokwim Delta Regional Energy Plan (Final Draft). 2016 June.

${ }^{14}$ State of Alaska Department of Commerce, Community, and Economic Development website. https://www.commerce.alaska.gov/dcra/DCRAExternal/community/Details/9ac24aaf-73bd-45f6-a5cdbe30f687c04d. Accessed 2017 May 24.

${ }^{15}$ Dennis Meiners, private communication, 28 Dec 2016.
} 


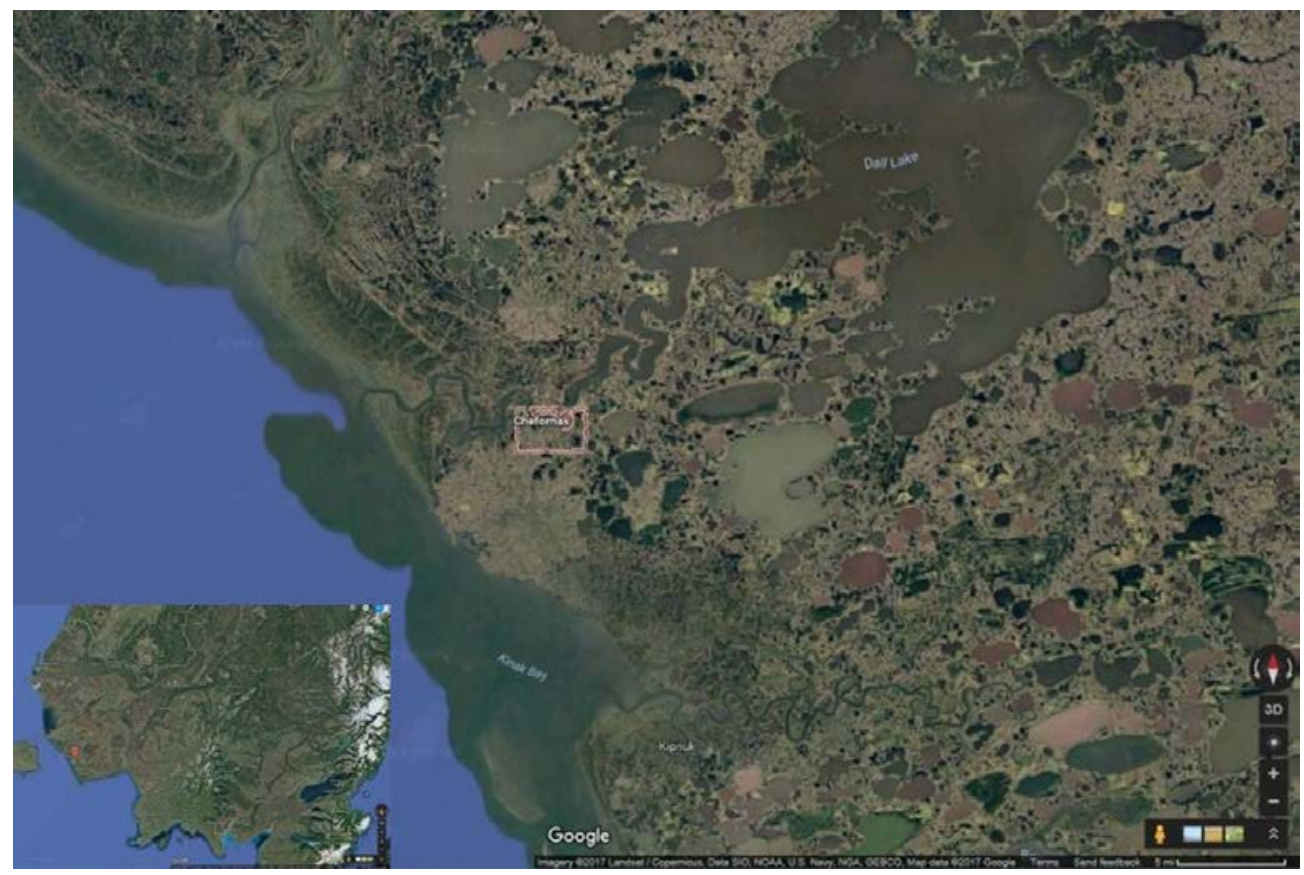

Figure 2-2: Area map of Chefornak. Source: Google Maps

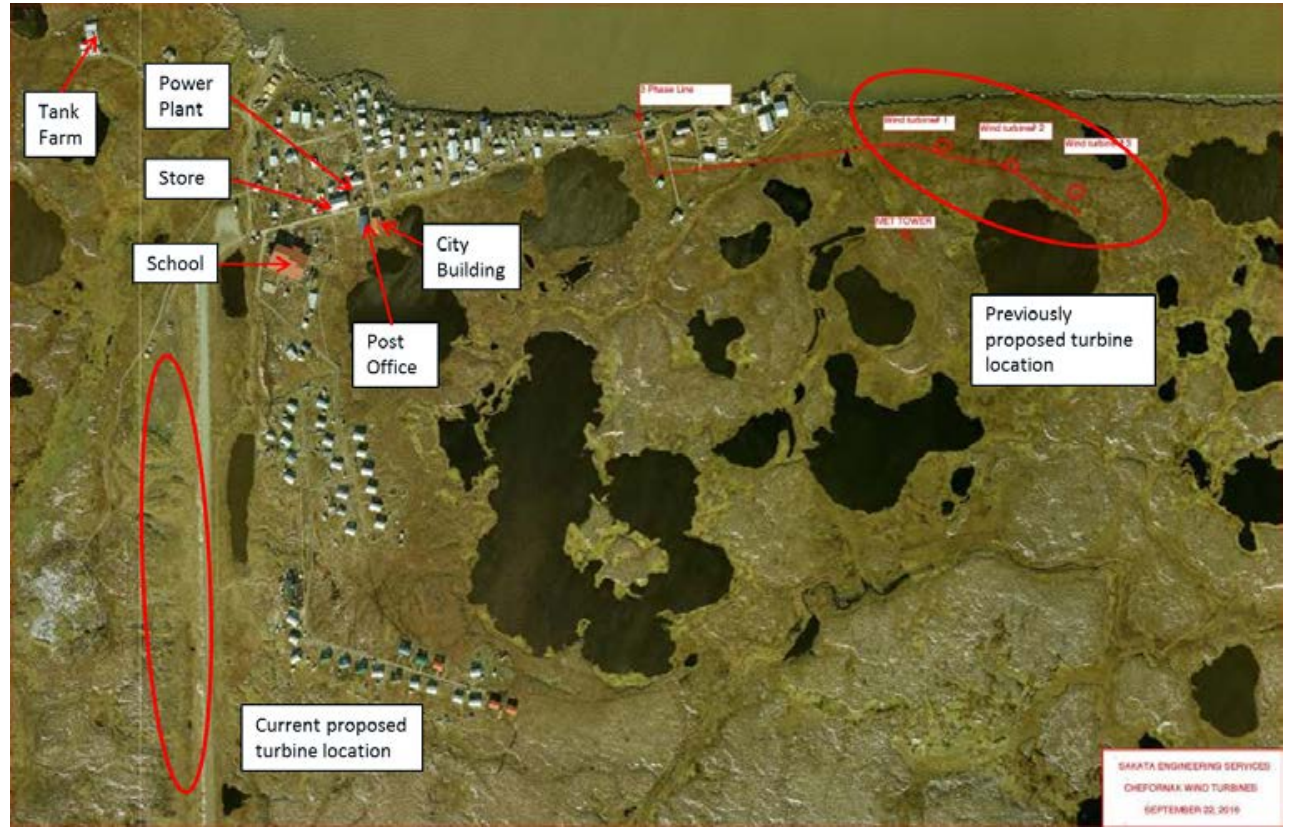

Figure 2-3: Aerial view of Chefornak. Source: Dennis Meiners 


\subsection{Community Electricity and Heating Infrastructure}

Like most remote Alaska communities, Chefornak is served by an isolated mini-grid. The Naterkaq Light Plant, a local utility, provides electricity to the community. The electrical plant has three diesel generator units rated at $371 \mathrm{~kW}, 371 \mathrm{~kW}$, and $179 \mathrm{~kW}$, respectively. Table 3-1 provides summary data on the three diesel generator units at the power plant. The plant has a heat recovery system that currently provides heat to the water and sewer pipes and the current washeteria. This system will also serve the new washeteria that is currently under construction. Currently the plant has no renewable generation. However, planning for the installation of three $100-\mathrm{kW}$ turbines is underway.

Table 3-1: Chefornak Generator Data. Source: Alaska Energy Authority; Village Power System Inventory (Inventory Conducted 2012 October 12)

\begin{tabular}{llll}
\hline & \multicolumn{1}{c}{ G-1 } & \multicolumn{1}{c}{ G-2 } & \multicolumn{1}{c}{ G-3 } \\
\hline Capacity (kW) & 371 & 371 & 179 \\
Engine make & John Deere & John Deere & John Deere \\
Engine model & 6125HF070 & 6125HF070 & 6081AFM75 \\
Generator make & Marathon & Marathon & Marathon \\
Generator model & 572RSL4027 & 572RSL4027 & 432RSL4013 \\
\hline
\end{tabular}

Diesel generator capital and O\&M cost data are difficult to obtain, and the existing data have a wide spread. Table 3-2 combines information from a study of diesel costs published by the Alaska Center for Energy and Power ${ }^{16}$ supplemented by information and rough costs gleaned from conversations with utility representatives and installers.

Fuel curve data are not specific to the units currently in the Chefornak power plant but rather represent typical performance for reasonably energy efficient units.

Table 3-2: Diesel Generator Cost and Performance Assumptions

\begin{tabular}{lrr}
\hline Rated Power (kW) & $\mathbf{1 7 9}$ & $\mathbf{3 7 1}$ \\
\hline Capital cost (\$) & $\$ 0$ & $\$ 0$ \\
Replacement cost (\$) & $\$ 73,600$ & $\$ 152,000$ \\
O\&M (\$/hour) & $\$ 15.64$ & $\$ 16.80$ \\
Lifetime (hours) & 60,000 & 100,000 \\
Marginal fuel consumption (gal/kWh) & 0.063 & 0.063 \\
No load fuel consumption (gal/hour) & 0.95 & 1.96 \\
\hline
\end{tabular}

Oil-fired stoves provide most of the heat required for space and water heating for Chefornak's residences and community building. Wood-fired stoves provide some (unknown) amount of heat to Chefornak's residences. A final source of heat is heat recovery from the diesel generators. This recovered heat is used to heat the washeteria.

\footnotetext{
${ }^{16}$ Green, N., Mueller-Stoffels, M., and Whitney, E. An Alaska Case Study: Diesel Generator Technologies. JRSE, submitted.
} 
The analysis assumes that the heat load described in Chapter 4 excludes the heat load met by wood burning stoves. The analysis assumes that the same amount of wood burning will occur regardless of the configuration of the power plant.

The analysis accounts for the heat recovered from the diesel generators. If less heat is produced due to reduced operation of the diesel generators (driven by increased RE production), the model captures this and increases the use of other sources to provide the needed thermal energy.

Diesel is used to generate electricity and for heating. This report refers to fuel used for electricity production as "diesel fuel." Fuel used for heating is referred to in this report as "heating oil." The fuel for these two purposes is distributed through different channels and is thus often priced differently. Diesel fuel is typically purchased in bulk by the utility. Heating oil, especially for individual residences, is typically distributed through retail channels. Some community buildings, such as schools, may be able to purchase fuel in bulk quantities at a lower unit price.

Table 3-3 shows diesel fuel consumption and cost for Fiscal Year (FY) 2012 through FY 2016. Due (at least in part) to a reported reduction in line losses, overall diesel consumption decreased over the time period. Average diesel fuel costs during the time period varied from \$4.14/gal to \$6.65/gal.

Table 3-3: Chefornak Diesel Fuel Consumption and Cost (FY 2012 - FY 2016). Source: Alaska Energy Authority; FY 2012 - FY2016 Annual PCE Statistical Reports by Community. http://www.akenergyauthority.org/Programs/PCE

\begin{tabular}{|l|rrrrr|c|}
\hline Year (Fiscal) & $\mathbf{2 0 1 2}$ & $\mathbf{2 0 1 3}$ & $\mathbf{2 0 1 4}$ & $\mathbf{2 0 1 5}$ & $\mathbf{2 0 1 6}$ & \multicolumn{1}{c|}{ Avg. } \\
\hline Avg. Cost (\$/gal) & $\$ 4.33$ & $\$ 5.21$ & $\$ 6.65$ & $\$ 4.55$ & $\$ 4.14$ & $\$ 4.98$ \\
Avg. Cost (\$/L) & $\$ 1.15$ & $\$ 1.39$ & $\$ 1.77$ & $\$ 1.21$ & $\$ 1.10$ & $\$ 1.32$ \\
\hline Fuel Used (gal) & 131,728 & 132,248 & 116,999 & 117,529 & 113,389 & \\
Fuel Used (L) & 497,932 & 499,897 & 442,256 & 444,260 & 428,610 & \\
\hline
\end{tabular}

Data are on heating oil consumption, and cost is less available. Based on estimated 2015 thermal consumption estimate of 7,905,052 $\mathrm{kWh}(26,991 \mathrm{MMBtu})^{17}$, heating oil consumption is estimated at 248,000 gal/year. According to one source ${ }^{18}$, the price of heating oil in 2016 in Chefornak was \$4.55/gallon. Historical heating price data for Chefornak are unavailable.

Diesel fuel prices and heating oil prices both track world oil prices. Currently oil prices are relatively low and are expected to stay that way for the short term. In the longer term, fuel prices are highly uncertain and likely to vary.

For diesel fuel, the analysis assumes an initial cost of \$4.50/gal (\$1.19/L). This is below the FY $2012-$ FY 2016 average cost but higher than the very low FY 2016 cost.

For heating oil, the analysis assumes an initial cost of $\$ 5.00 /$ gal $(\$ 1.32 / \mathrm{L})$. This assumes that, like for diesel fuel, the 2016 cost is unusually low.

As a conservative assumption, this analysis uses fuel prices that are toward the low end of the price band experienced over the past few years. The EE and RE measures considered in this analysis typically

${ }^{17}$ AEA. "Remote Alaska Communities Energy Efficiency Competition: Phase II Summary and Strategic Energy Efficiency Plan-Chefornak.” Aug 19, 2016.

${ }^{18}$ Ibid. 
involve significant capital expenditures. The cost-effectiveness of these measures is often very sensitive to fuel prices. Using a low estimate for future fuel prices reduces the fuel price risk of EE and RE investments. 


\subsection{Electrical and Thermal Loads}

\subsection{Loads Overview}

Figure 4-1 shows electrical and thermal end use energy consumption. Of the two categories, heating dominates, accounting for more than $80 \%$ of combined heating and electricity end use. This relative ratio of thermal to electricity end use is in line with other communities in the region. ${ }^{19}$ Figure $4-2$ shows the relative fuel consumption of the two categories. While the ratio is less skewed than for energy end use, two-thirds of combined fuel consumption goes to meet thermal loads. A key take away from these pie charts is that any attempt to seriously reduce imported energy must address thermal loads.

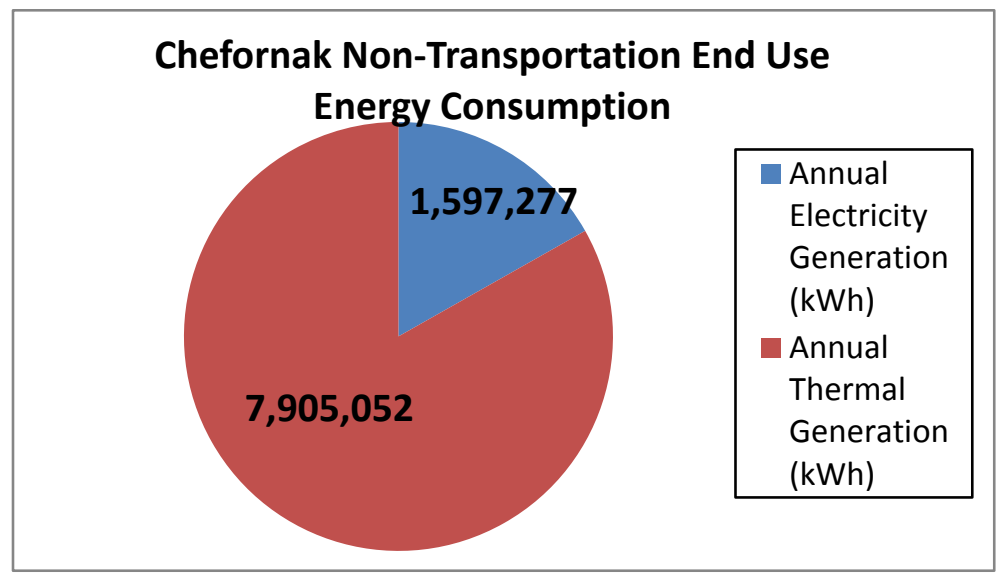

Figure 4-1: End use energy consumption. Source: Alaska Energy Authority; Remote Alaska Communities Energy Efficiency Competition: Phase II Summary and Strategic Energy Efficiency Plan - Chefornak; 2016 Aug 19

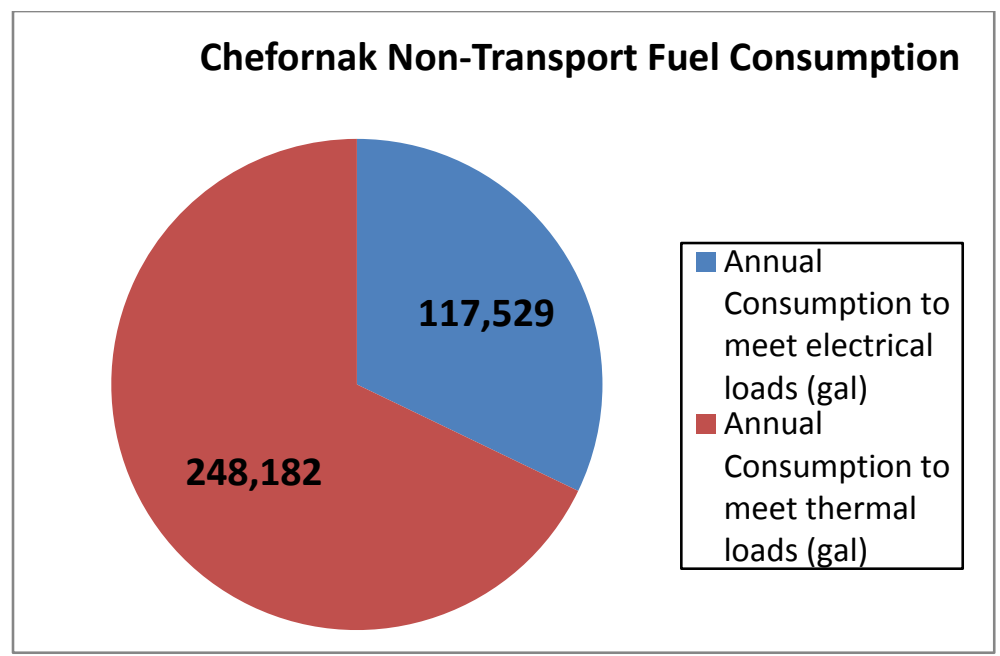

Figure 4-2: Fuel consumption by category. Source: Alaska Energy Authority; Remote Alaska Communities Energy Efficiency Competition: Phase II Summary and Strategic Energy Efficiency Plan - Chefornak; 2016 Aug 19

\footnotetext{
${ }^{19}$ Alaska Energy Authority. The Alaska Affordable Energy Strategy: Methodology, Findings, \& Recommendations; 2017; http://www.akenergyauthority.org/Portals/0/DNNGallery/uploads/2017/1/23/AkAESMFR22217.pdf.
} 


\subsection{Electrical Loads}

\subsubsection{Current Electrical Loads}

Electrical generation and consumption data for Chefornak is well documented. Annual and monthly data are collected and published under the Power Cost Equalization program. In addition, 10-minute time series data for 2015 and 2016 were collected as part of a pending wind turbine project. This data set had significant gaps, with an overall data recovery rate of 66\%. A full 2015 data set was created by starting with the 2015 data. Gaps were filled by data from the same time period in 2016 (when available) or by copying data adjacent to the gaps.

Figure 4-3 shows the 2015 time series electrical load data with the gaps filled in. Figure 4-4 (box plot), Figure 4-5 (monthly diurnal load profiles), and Figure 4-6 (load histogram) characterize the 2015 data set. Total consumption for the year totaled $1,570,000 \mathrm{kWh}$. The peak load was $314 \mathrm{~kW}$, and the average load was $179 \mathrm{~kW}$. As can be seen, consumption is highest in the winter and spring and lowest in the summer.

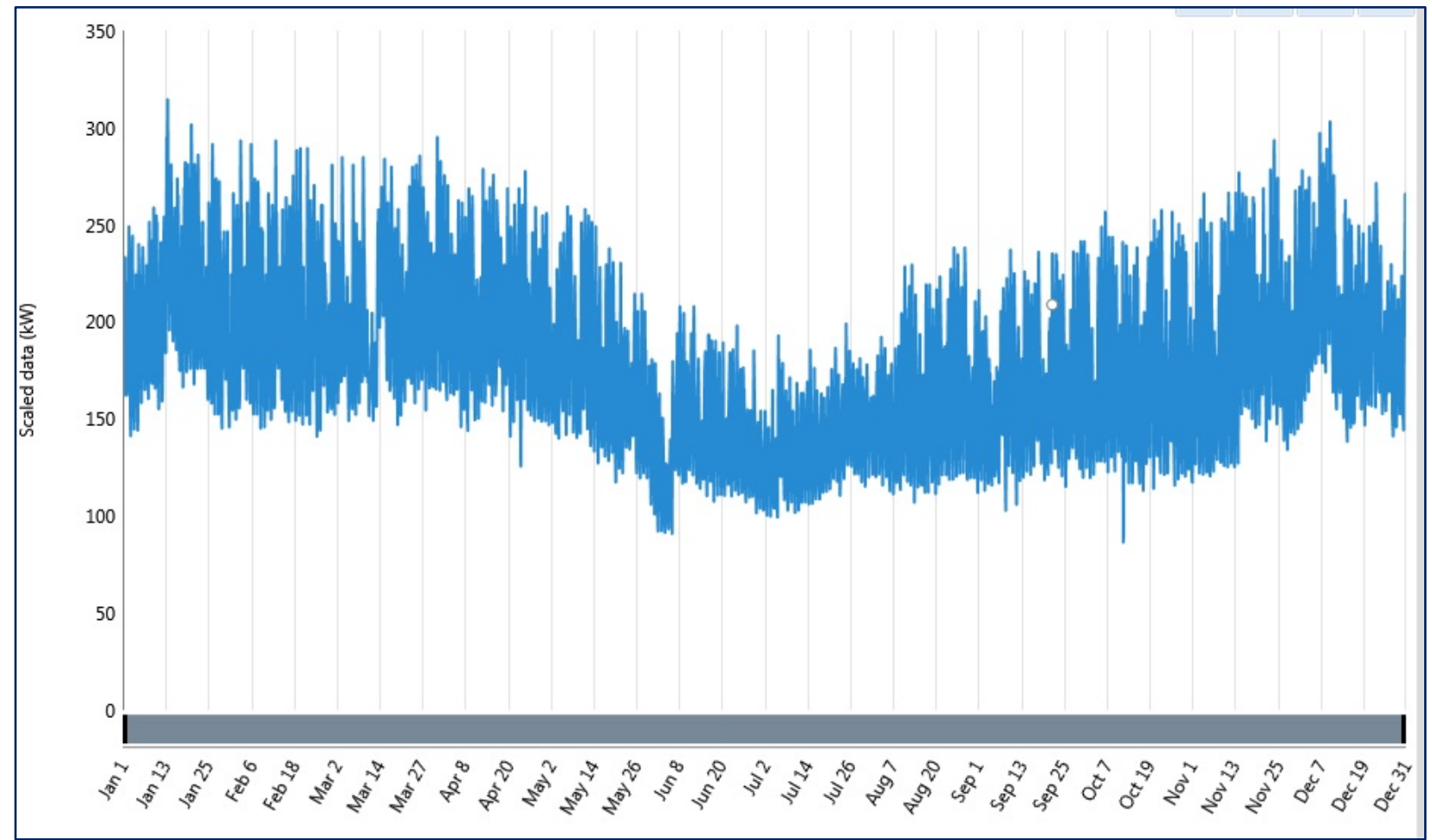

Figure 4-3: Chefornak electrical load (2015). Source: Time series data provided by Dennis Meiners 


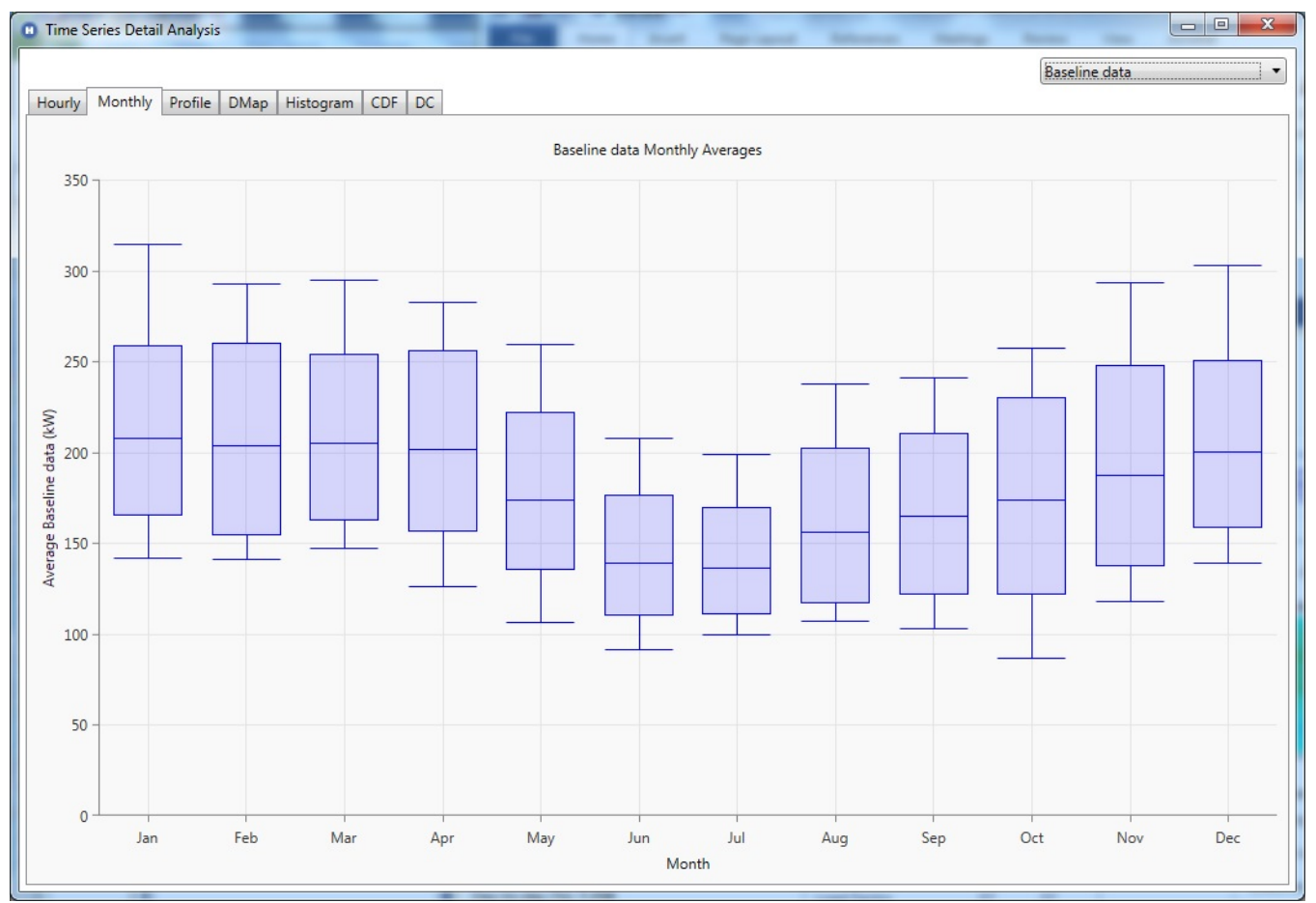

Figure 4-4: Chefornak electrical load (2015) box plot. Source: Time series data provided by Dennis Meiners

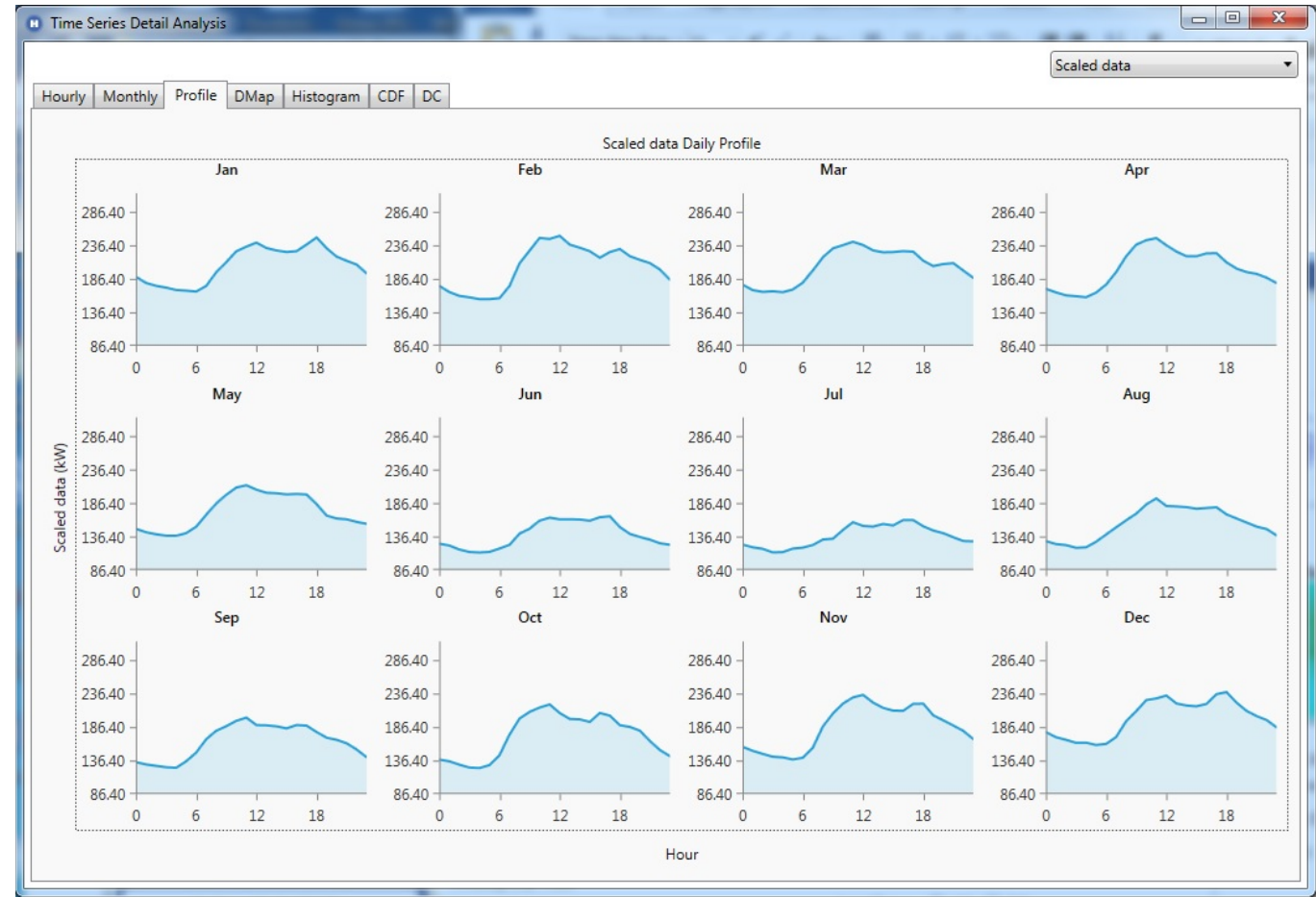

Figure 4-5: Chefornak electrical load (2015) monthly diurnal profiles. Source: Time series data provided by Dennis Meiners 


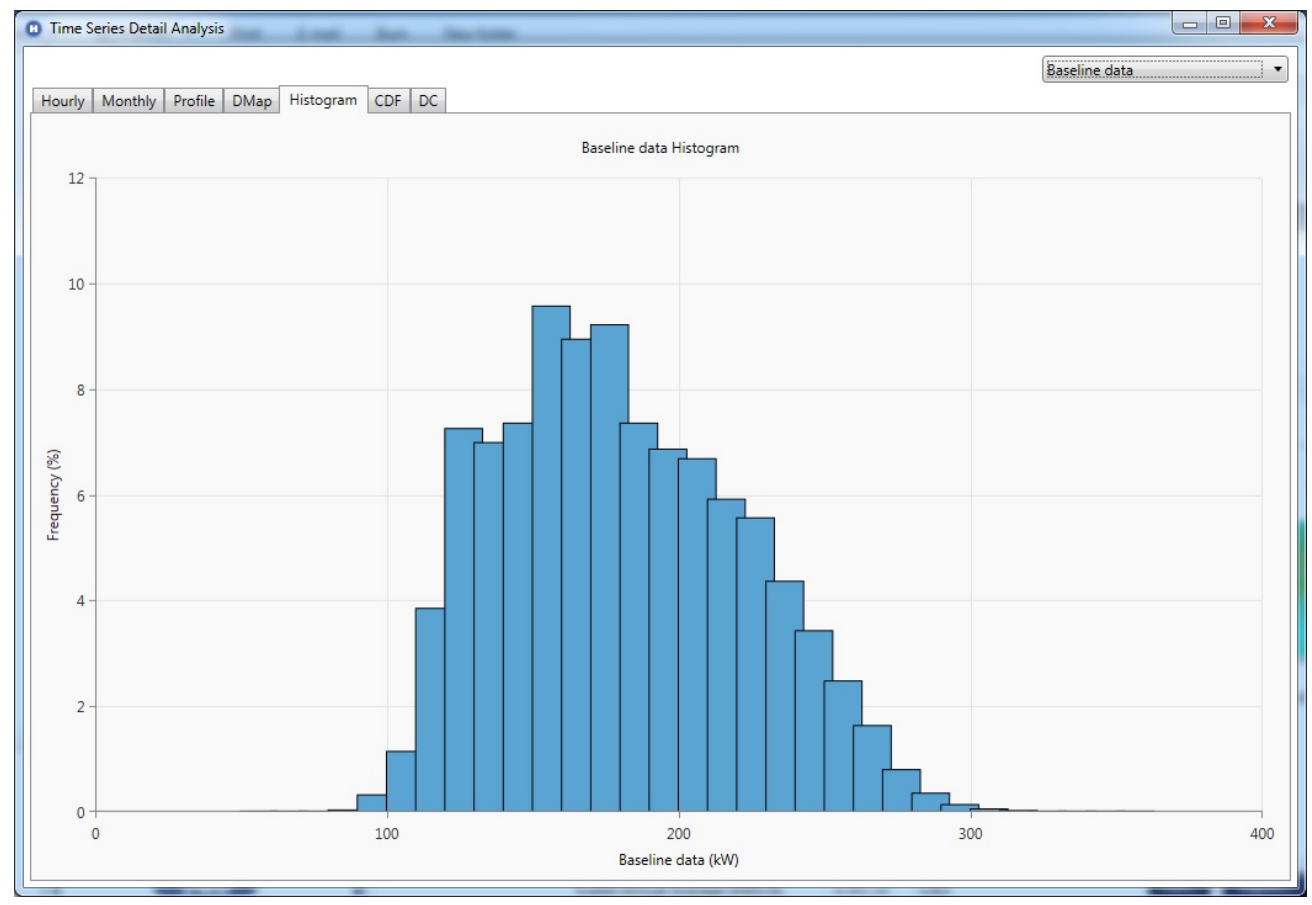

Figure 4-6: Chefornak electrical load (2015) histogram. Source: Time series data provided by Dennis Meiners

\subsubsection{Future Electrical Load (Modeling Assumptions)}

Figure 4-7 shows Chefornak electricity production and consumption data (by fiscal year) for the period FY 2012 to FY 2016. ${ }^{20}$ The values for production and consumption sharply converge after FY 2013 due to a significant reduction in reported line losses (from $30 \%$ to $40 \%$ to $\sim<10 \%$ ). This reduction in line losses $^{21}$ allowed overall consumption to increase over the time period (from roughly 1,200,000 kWh to 1,400,000 kWh) while overall generation decreased.

The annual consumption trends upward but with significant year-to-year variation. With only five data points, the year-to-year variation complicates efforts to determine the overall growth rate in annual consumption. For example, the average annual growth in consumption for FY 2012 to FY 2016 is 3.0\%, while the average growth rate for FY 2013 to FY 2015 is 15.8\%.

\footnotetext{
${ }^{20}$ Alaska Energy Authority. FY 2012 - FY2016 Annual PCE Statistical Reports by Community. http://www.akenergyauthority.org/Programs/PCE.

${ }^{21}$ Other than distribution line upgrades, the reduction in reported line losses could be due (in whole or in part) to reasons such as a meter audit or billing errors. Source: Marc Mueller-Stoffels; private communication; September 2017.
} 


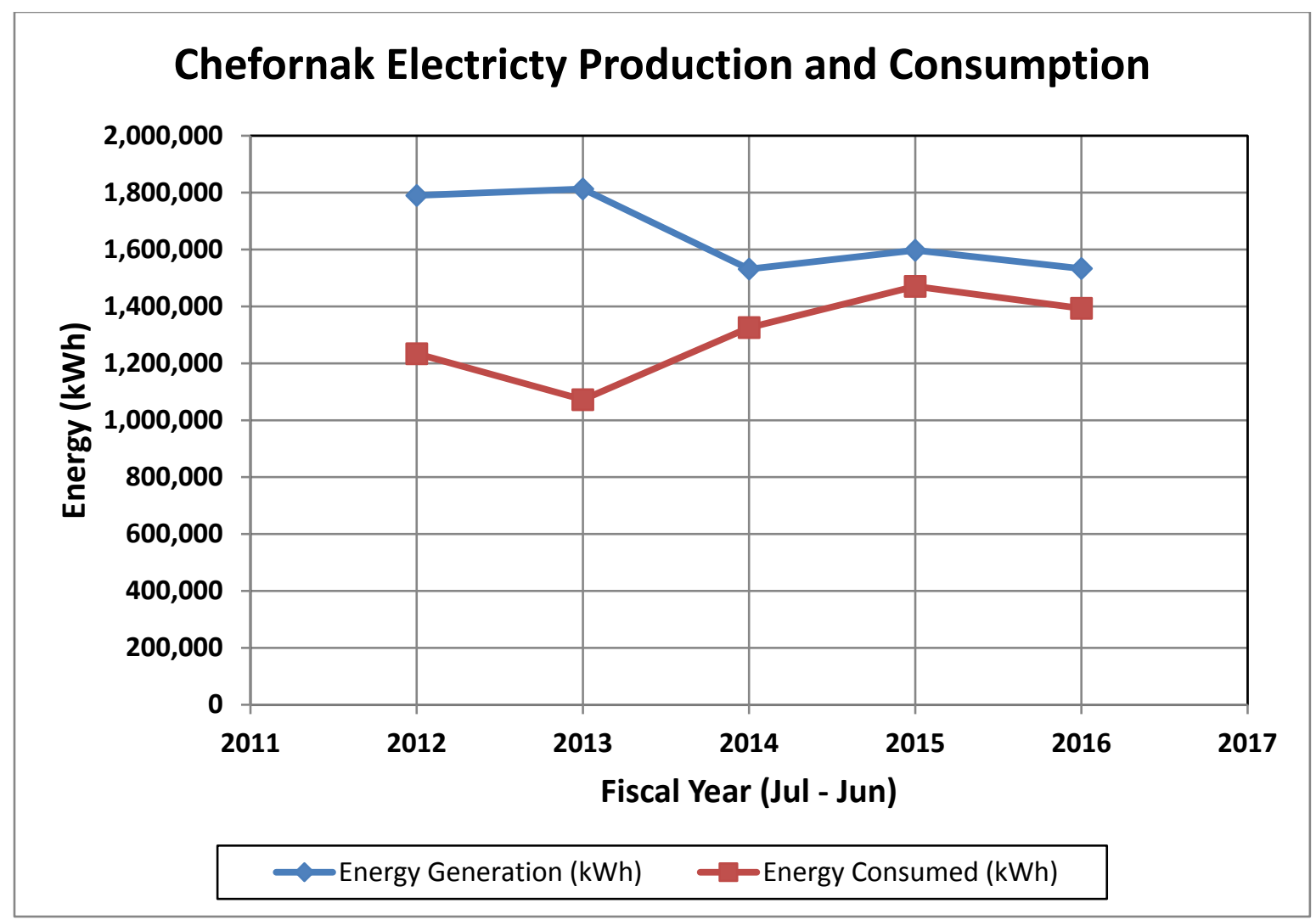

Figure 4-7: Chefornak electricity generation and consumption. Source: Alaska Energy Authority; FY 2012 - FY2016 Annual PCE Statistical Reports by Community. http://www.akenerqyauthority.org/Programs/PCE

The analysis assumes a system installed in 2018 with a lifetime of 20 years. The analysis uses the estimated load for the mid-point of the system lifetime, which would be 2029. Going forward from 2016, the analysis assumes that the annual electricity consumption growth rate slows, due to energy efficiency, to match the long-term population growth rate of $1.2 \%$ per annum. Assuming a $1.2 \%$ growth rate and assuming the same line loss ratio as in 2016 (9.1\%) leads to an estimate for 2029 generation of 1,790,000 $\mathrm{kWh}$. This represents a 17\% increase from 2016. The resulting average and peak loads are $210 \mathrm{~kW}$ and $367 \mathrm{~kW}$ respectively.

\subsection{Thermal Loads}

\subsubsection{Current Thermal Load}

In contrast to the data on electricity generation and associated fuel consumption, much less data are available on thermal loads and heating oil use. An initial thermal load time series file was created using a building energy model and a regional climate data file. ${ }^{22}$ The initial thermal load model was then scaled using annual thermal load estimate (for 2015) from a 2016 energy efficiency analysis. ${ }^{23}$ The study estimated the total annual thermal consumption to be 195,616 Diesel Gallon Equivalents [27,991

22 TMY3 climate data for Bethel, Alaska.

${ }^{23}$ Alaska Energy Authority (AEA). Remote Alaska Communities Energy Efficiency Competition: Phase II Summary and Strategic Energy Efficiency Plan-Chefornak. Aug 19, 2016. 
MMBTU, 7,905,344 kWh]. The final thermal load file is shown in Figure 4-8. Not surprisingly, the thermal load shows a strong seasonal dependence. The thermal load is high in the winter and low in the summer.

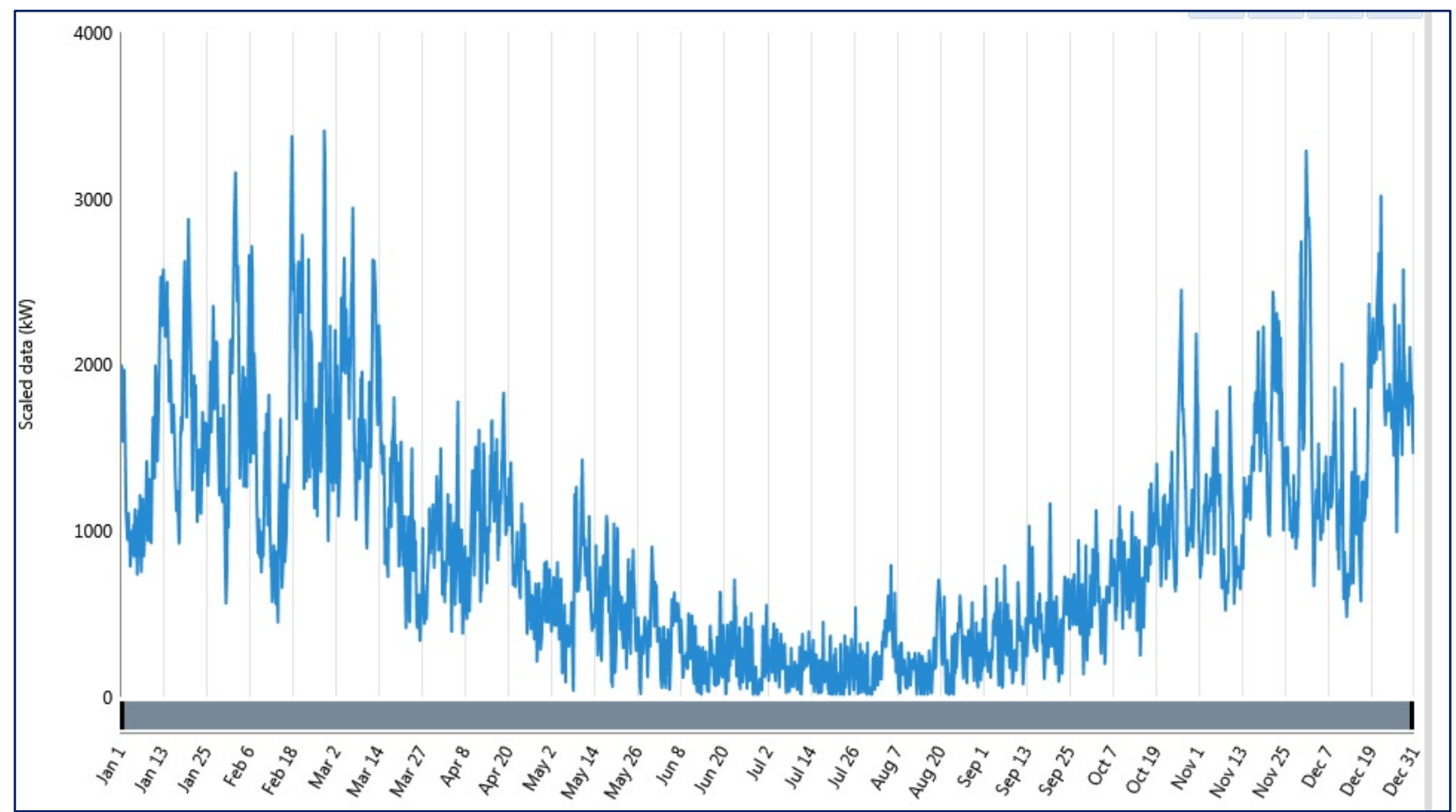

Figure 4-8: Chefornak thermal load (2015). Source: Time series data file created by Jesse Dean (NREL)

\subsubsection{Future Thermal Load (Modeling Assumptions)}

Despite some significant new construction, the heating load in Chefornak apparently stayed constant between 2010 and 2015. ${ }^{24}$ As a base case, this analysis assumes the future thermal load growth rate is half of the population growth rate, or $0.6 \%$. This assumes that any new infrastructure is more energy efficient than the existing infrastructure. The thermal load growth rate is assumed to be less than the electrical load growth rate because, as shown in Chapter 5 , there are more opportunities for thermal efficiency improvements than for electrical efficiency improvements. Extrapolating the thermal load out to 2029 results in estimated thermal consumption of 8,596,000 kWh/year.

\footnotetext{
${ }^{24}$ Alaska Energy Authority. Remote Alaska Communities Energy Efficiency Competition: Phase II Summary and Strategic Energy Efficiency Plan-Chefornak. Aug 19, 2016.
} 


\subsection{Energy Efficiency}

In many instances, saving a unit of energy is less expensive than generating a unit of energy. This chapter reviews (at a high level) various EE options. Cost and performance assumptions are presented for the options considered in the analysis.

\subsection{End-Use Electrical Energy Efficiency}

Like the Alaska remote communities in general, per-capita electricity use in Chefornak is low compared to U.S. and Alaska averages; thus dramatic decreases in electricity consumption are unlikely. This does not preclude continuing modest improvements due to actions such as replacement of appliances with more energy efficient models and conversion of incandescent and fluorescent lighting to light-emitting diode lighting. However, the reasons underlining energy consumption have not been assessed, so outside factors (such as a large change in the cost of energy or new infrastructure) could modify consumption rates.

Based on a 2016 energy audit, ${ }^{25}$ a 2016 residential survey, ${ }^{26}$ data on the Alaska Affordable Energy Model, ${ }^{27,}{ }^{28}$ and Alaska Housing Finance Corporation weatherization data, ${ }^{29,30}$ it is estimated that overall electricity use reductions on the order of $5 \%$ to $10 \%$ are possible at a cost of $\sim$ \$1.15 per annual kilowatthour saved. Although seemingly a relatively high cost, the current (FY 2016) post-PCE residential rate of electricity of $\$ 0.23 / \mathrm{kWh}^{31}$ results in a 5-year payback on electrical EE upgrades.

\subsection{End-Use Thermal Energy Efficiency}

Energy efficiency efforts in Alaska have focused on weatherization to reduce building thermal loads. Based on a 2016 energy audit, ${ }^{32}$ a 2016 residential survey, ${ }^{33}$ data on the Alaska Affordable Energy

25 AEA. " Remote Alaska Communities Energy Efficiency Competition: Phase II Summary and Strategic Energy Efficiency Plan-Chefornak." 2016 Aug 19.

${ }^{26}$ Dennis Meiners, private communication, 28 Dec 2016.

27 Alaska Affordable Energy Model. http://modelresults.akenergyinventory.org/m0.24.6_d0.24.0/Chefornak/residential_energy_efficiency.html. Accessed 28 May 2017.

${ }^{28}$ Alaska Affordable Energy Model. http://model-results.akenergyinventory.org/m0.24.6_d0.24.0/Chefornak/nonresidential_energy_efficiency.html. Accessed 28 May 2017.

29 “AK Regional Wx Stats.xlsx” Spreadsheet provided by Neil McMahon of the Alaska Energy Authority. Data in the spreadsheet are from the Alaska Housing Financing Corporation.

30 “AK Residential Wx Model Data.xlsx” Spreadsheet provided by Neil McMahon of the Alaska Energy Authority. Data in the spreadsheet are from the Alaska Housing Financing Corporation.

${ }^{31}$ Alaska Energy Authority. FY2016 Annual PCE Statistical Report by Community. http://www.akenergyauthority.org/Programs/PCE. The 5-year payback is the payback to the home owner assuming the PCE subsidized price of electricity. The payback to society in general can be conservatively calculated using the marginal cost of electricity. Using the FY 2016 fuel cost of \$4.14/gallon and assuming a marginal fuel consumption of $0.063 \mathrm{gal} / \mathrm{kWh}$ results in a marginal cost of electricity of $\$ 0.26 / \mathrm{kWh}$. The resulting payback is 4.4 years.

32 AEA. Remote Alaska Communities Energy Efficiency Competition: Phase II Summary and Strategic Energy Efficiency Plan-Chefornak. 2016 Aug 19.

33 Dennis Meiners, private communication, 28 Dec 2016. 
Model, ${ }^{34}$ and Alaska Housing Finance Corporation weatherization data, ${ }^{3536}$ it is estimated that overall thermal use reductions on the order of $30 \%$ are possible at a cost of $\sim \$ 1.00$ per annual $\mathrm{kWh}_{\text {th }}$ saved.

\subsection{Energy Efficiency Sensitivity Analysis}

End-use electrical and thermal EE can be modeled by scaling down the values electrical and thermal time series load profiles. The analysis included a sensitivity study of two EE scenarios. The "no-EE" scenario assumes no EE implementation. The second scenario, the "with-EE" case, assumed a 5\% (89,500 kWh) reduction in the electricity consumption (for 2029) and a $25 \%\left(859,600 \mathrm{kWh}_{\text {th }}\right)$ reduction in the thermal consumption. Total implementation cost is estimated to be $\$ 2,250,000$ ( $\$ 100,000$ for the electrical EE upgrades and \$2,150,000 for the thermal EE upgrades).

\subsection{Reduction in Electrical System Distribution Line Losses}

As shown in Figure 4-7, reported line losses greatly decreased after FY 2013. The analysis assumes the same level of line losses as reported in FY 2016 (9.1\%).

\subsection{Heat Recovery}

Heat recovery is the capture of a portion of the heat from the exhaust of diesel generators. This captured heat can provide space heating to a power plant and to nearby buildings (typically commercial or community buildings). The power plant currently has a heat recovery system that is used to heat the washeteria. Recovered heat will serve the new washeteria that is currently under construction.

The analysis models heat recovery assuming a 30\% heat recovery ratio, the default value in HOMER. This means that $30 \%$ of the remaining energy in the diesel fuel, after electricity production, is captured to meet thermal loads. For example, if in a given time step electricity production equaled $30 \%$ of the energy in diesel fuel, the thermal energy capture would be $0.3 \times 0.7=0.21$, or $21 \%$ of the energy in the fuel. Thermal energy extraction from diesel-produced electricity was explicitly modeled in the study, with any reductions in recovered heat due to the reduced fuel use being compensated with other sources.

\subsection{Use of Excess Renewable Energy Electricity to Meet Thermal Loads (Modeling Assumption)}

In situations where the RE component(s) of a high (RE)-contribution hybrid systems often produce electricity in excess of both the electrical load at the time and the available storage capacity, it often makes sense to use this excess energy that would otherwise be wasted (spilled) to help meet the thermal load. There are several ways to do this. One method is to use the excess RE to heat the water (or other fluid) used in the heat recovery loop.

\footnotetext{
${ }^{34}$ Alaska Affordable Energy Model. http://modelresults.akenergyinventory.org/m0.24.6_d0.24.0/Chefornak/residential_energy_efficiency.html. Accessed 28 May 2017.

35 “AK Regional Wx Stats.xlsx.” Spreadsheet provided by Neil McMahon of the Alaska Energy Authority. Data in the spreadsheet are from the Alaska Housing Financing Corporation.

36 “AK Residential Wx Model Data.xlsx.” Spreadsheet provided by Neil McMahon of the Alaska Energy Authority. Data in the spreadsheet are from the Alaska Housing Financing Corporation.
} 
Another method, the one used in this analysis, is to use this excess RE in so-called "electric thermal stoves," which are essentially electric heaters. These are separately metered and only operated when excess RE is available. An electric thermal stove consists of a resistive heating element that converts electricity to heat and bricks that can store the heat and release it over time. A typical electric thermal stove has $6 \mathrm{~kW}$ of resistive heating elements and can store up to $30 \mathrm{~kW}_{\text {th }}$ of heat. The software used in the analysis does not account for thermal energy storage; thus there is more flexibility in reality than can be captured in the model. The capital cost used in the analysis is a $\$ 10,000$ fixed cost to set up the communications and control network and $\$ 3,000$ per electric thermal stove $(\$ 500 / \mathrm{kW})$. The lifetime of the stoves is assumed to be 20 years. 


\subsection{Wind Turbine Technology}

Currently, Chefornak has no renewable generation. However, planning for the installation of three 100$\mathrm{kW}$ turbines is underway.

\subsection{Wind Resource}

Chefornak has an excellent wind resource. Figure 6-1 characterizes the wind resource based on data collected from 6 June 2012 to 8 July 2013. A report created by V3 Energy ${ }^{37}$ provides a more detailed analysis of the collected wind data.

The data for the period 1 July 2012 - 30 Jun 2013 were used to create the time series file used in the analysis. The gap-filling function in Windographer ${ }^{38}$ was used to fill gaps in the data set to create a continuous time series data set. The data for period 1 Jan 2013 - 30 June 2013 was moved in front of the remaining data to create a time series file running from Jan 1 - Dec 31. Compared to the original data, the process of filling in the gaps reduced the $29-\mathrm{m}$ average wind speed from $7.49 \mathrm{~m} / \mathrm{s}$ to $7.44 \mathrm{~m} / \mathrm{s}$. Finally, based on a comparison with a long-term MERRA dataset, the average wind speed was scaled down slightly to $7.27 \mathrm{~m} / \mathrm{s}$

On a seasonal basis, the wind resource generally matches the electrical and thermal loads. Like the loads, the wind resource is higher in the winter months and lower in the summer. The diurnal profile is fairly flat but does show a mid- to late afternoon peak.

\footnotetext{
${ }^{37}$ Vaught, Douglas; V3 Energy. Chefornak, Alaska Wind Resource Assessment Report. V3 Energy LLC; June 13, 2014.

${ }^{38}$ Windographer version 3.3.10 (October 8, 2015). https://www.windographer.com/.
} 


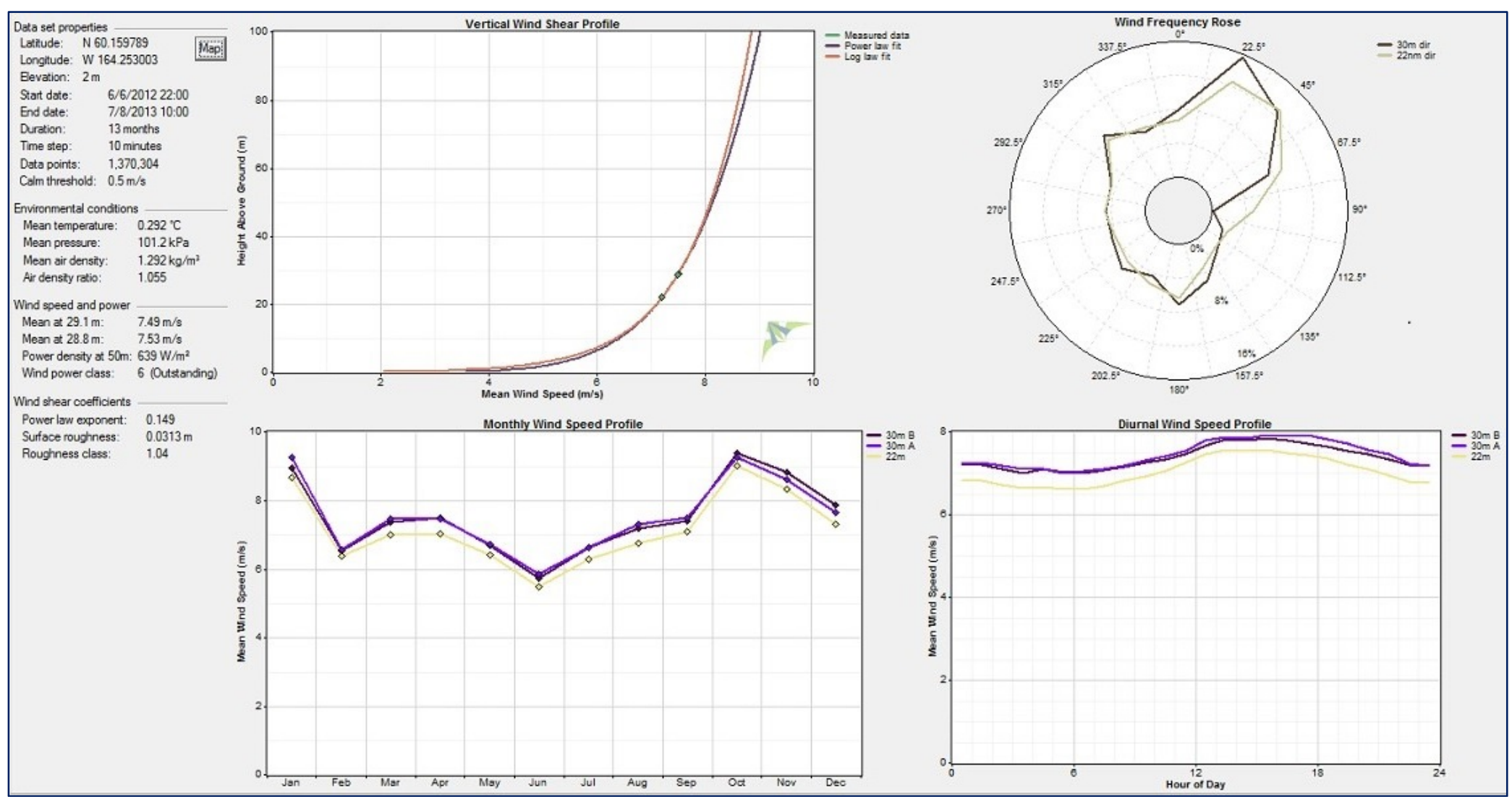

Figure 6-1: Chefornak wind data summary (6 June 2012 - 8 July 2013). Source: Based on data provided by Dennis Meiners 


\subsection{Wind Turbine Cost and Performance}

As previously mentioned, a project is underway to install three "Frontier 24 " $100-\mathrm{kW}$ wind turbines at Chefornak. This turbine model, which is currently under development, is a remanufactured and upgraded Windmatic 17S turbine. Remanufacturing and upgrades include the following:

- Increased rotor diameter (from $17 \mathrm{~m}$ to $24 \mathrm{~m}$ )

- Renewed drive train rolling and contact elements

- Upgraded controller with remote diagnostics

- Four quadrant drive

- Option to mount on a 50-m tilt-up tower.

The uncertified turbine performance-based power curve is provided in Figure 6-2. The turbines will be installed on 50-m towers.

The analysis assumes an overall 15\% loss factor to account for electrical losses and lower overall performance due to the remote location.

\begin{tabular}{|c|c|}
\hline $\begin{array}{c}\text { Wind Speed } \\
(\mathrm{m} / \mathrm{s})\end{array}$ & Power (kW) \\
\hline 0 & 0 \\
\hline 1 & 0 \\
\hline 2 & 0 \\
\hline 3 & 0 \\
\hline 4 & 9.3 \\
\hline 5 & 17.3 \\
\hline 6 & 28.7 \\
\hline 7 & 43.5 \\
\hline 8 & 59.3 \\
\hline 9 & 73.2 \\
\hline 10 & 84.3 \\
\hline 11 & 92.1 \\
\hline 12 & 97.4 \\
\hline 13 & 100.9 \\
\hline 14 & 102.9 \\
\hline 15 & 103.5 \\
\hline 16 & 102.6 \\
\hline 17 & 100.2 \\
\hline 18 & 96.4 \\
\hline 19 & 90.7 \\
\hline 20 & 82.6 \\
\hline
\end{tabular}

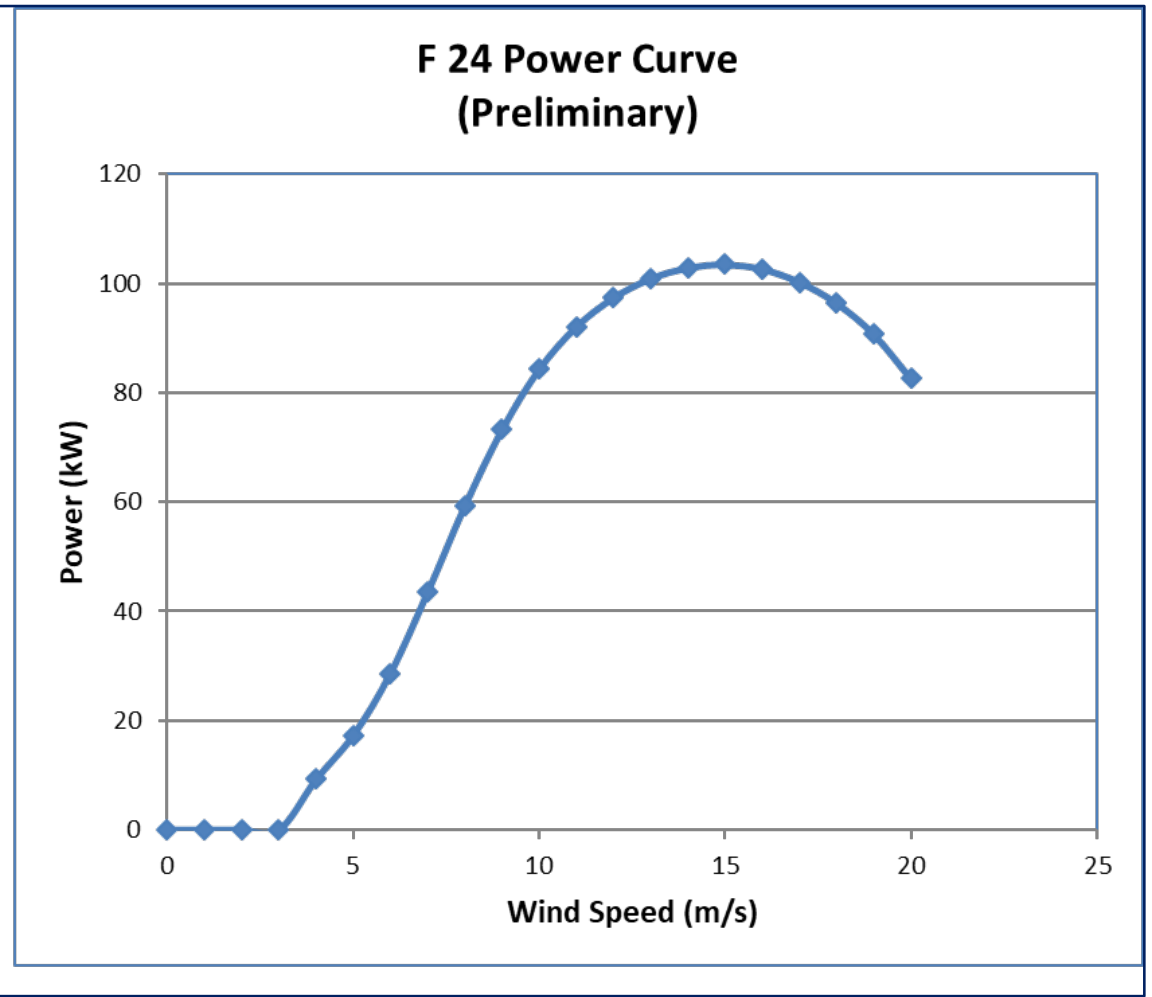

Figure 6-2: Preliminary Frontier F24 power curve. Source: Dennis Meiners (Intelligent Energy Systems) 
Table 6-1 shows the cost estimates used in the analysis. Initial capital costs are based on discussions with the system integrator (AMP partner Dennis Meiners). The installed turbine capital cost is estimated at $\$ 700,000$ per turbine with some economies of scale for additional turbines. A fixed cost of $\$ 200,000$ is added to account for the cost of integrating the wind turbines with the diesels. The analysis assumes a wind turbine lifetime of 20 years. Replacement costs are set at $80 \%$ of initial capital costs (without the fixed cost). This assumes some combination of re-use of some of the original infrastructure and cost reductions. O\&M costs are based on a study of wind turbine costs in Alaska. ${ }^{39}$

Table 6-1: Frontier F24 estimated costs. Source for capital cost: Dennis Meiner (Intelligent Energy Systems), Alaska Center for Energy and Power. Source O\&M costs: Vandermeer, J., Mueller-Stoffels, M., and Whitney, E., An Alaska Case Study: Wind Power Technology. JRSE, submitted.

\begin{tabular}{llll} 
\# Turbines & Capital Cost $(\$)$ & Repl. Cost $\mathbf{\$}$ ) & O\&M (\$/year) \\
\hline 1 & $\$ 900,000$ & $\$ 560,000$ & $\$ 17,500$ \\
2 & $\$ 1,565,000$ & $\$ 1,092,000$ & $\$ 34,125$ \\
3 & $\$ 2,195,000$ & $\$ 1,596,000$ & $\$ 49,875$ \\
4 & $\$ 2,790,000$ & $\$ 2,072,000$ & $\$ 64,750$ \\
5 & $\$ 3,350,000$ & $\$ 2,520,000$ & $\$ 78,750$ \\
\hline
\end{tabular}

\footnotetext{
${ }^{39}$ Vandermeer, J., Mueller-Stoffels, M., and Whitney, E. An Alaska Case Study: Wind Power Technology. JRSE, submitted.
} 


\subsection{Solar Photovoltaic Technology}

\subsection{Solar Resource}

Figure 7-1 shows the solar resource for Chefornak used in the analysis. With an average global horizontal irradiance of $2.5 \mathrm{kWh} / \mathrm{m}^{2} /$ day, the resource is modest. Not surprisingly, the solar resource shows extreme seasonal variation, with the bulk of the solar resource available from mid-spring to mid-autumn. On a seasonal basis, the solar resource poorly matches the electric load, which peaks in the winter.

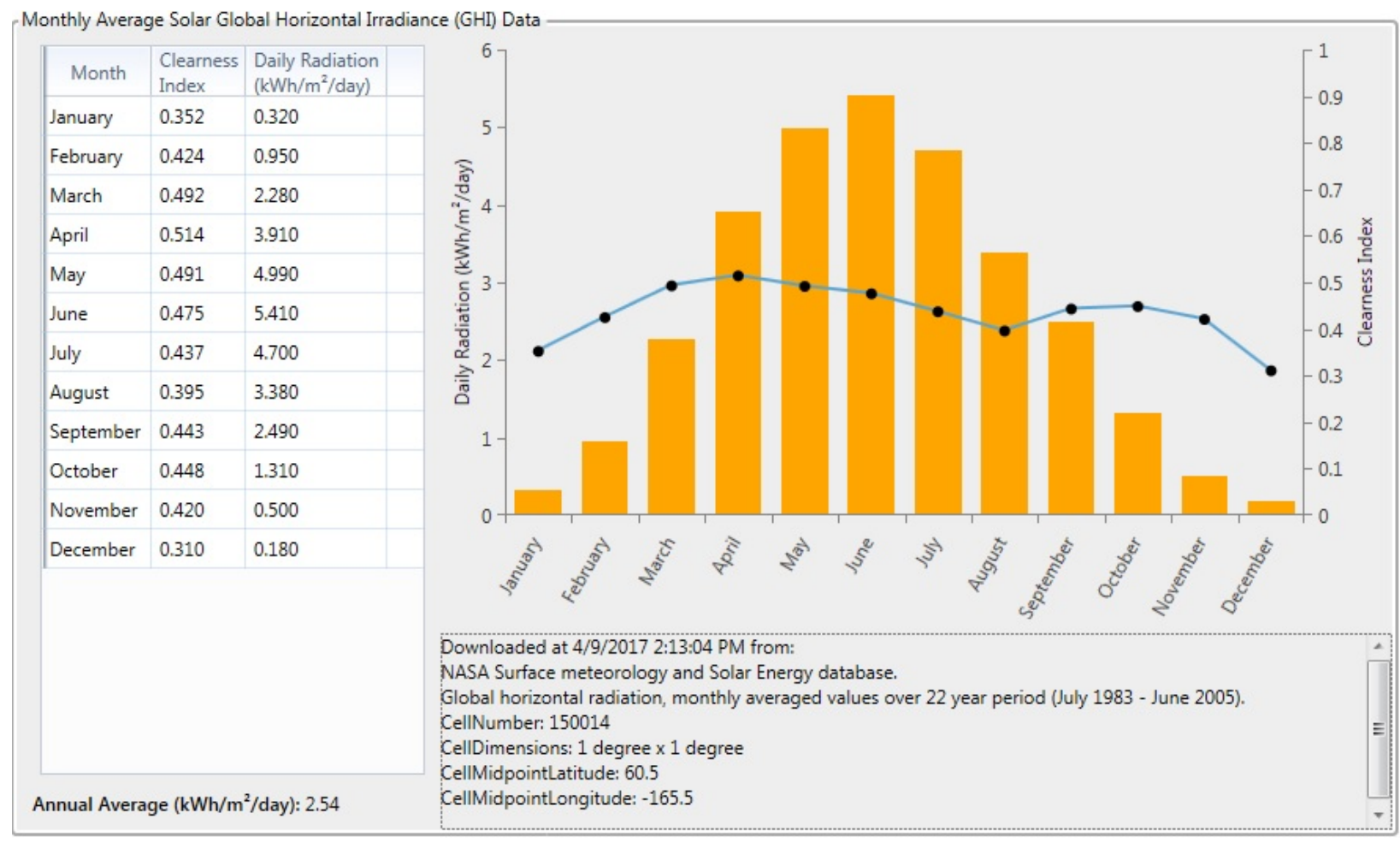

Figure 7-1: Chefornak solar resource. Source: NASA Surface Meteorology and Solar Energy database

\subsection{Solar PV Costs}

PV costs have dropped precipitously in recent years. The analysis uses an initial capital cost of $\$ 5,000 / \mathrm{kW}$. This is a premium over costs in the Continental United States but lower than the cost of previous solar projects in Alaska. This cost is roughly in line with currently planned projects.

The minimum PV size examined in the analysis is $25 \mathrm{~kW}$. This size was determined to be the minimum size that would make a difference to the overall system. It would certainly be possible to install a smaller PV system, although the overall cost effect would be minimal. 


\subsection{Integration, Storage, and Converters}

Key components of a high renewables contribution micro-grid are integration, storage, and converters. Integration refers to the controllers that monitor the system state, control the flow of energy, and turn on and off the various items of equipment to ensure that the load is met and the system stays stable. This whole field is seeing rapid development and declining costs. Because these three items are usually bundled together, it is difficult to disaggregate their individual costs.

One particular integration challenge is diesel-off operation. In addition to providing energy, the diesel generator also provides reactive power, voltage control, and frequency control. If the diesel generator is turned off, then some other means must be used to provide these services. Until recently, it was common to use a synchronous condenser to provide reactive power and frequency control during diesel-off operation. More recently, so-called "grid forming inverters” are taking over this role.

Storage can come in several forms such as batteries, flywheels, and capacitors. Batteries are most commonly used. Traditionally, lead-acid batteries have been the most commonly used batteries. More recently, lithium-ion batteries have become more popular due to their better performance and decreasing cost. Batteries size is given in terms of maximum discharge capacity, energy storage, or both. A given battery will have a fixed ratio of maximum discharge capacity to storage capacity. Batteries can be manufactured for increased discharge capacity or increased storage. This analysis assumes "generic" lithium-ion batteries and did not extend to optimizing the ratio of discharge capacity to storage capacity.

Converters are used to convert AC electricity to DC electricity (rectifiers) and DC electricity to AC electricity (inverters). Converters are needed when a given system includes both AC and DC equipment and/or electrical loads.

Integration costs are estimated at roughly $\$ 300,000$ fixed. The software used in the analysis does not make direct provision, as far as cost or performance, for integration. The analysis therefore divides this fixed cost between the wind turbines $(\$ 200,000)$, the storage $(\$ 50,000)$, and the converter $(\$ 50,000)$.

Table 8-1 shows the cost curves used in the analysis for the batteries and the converters. Replacement costs are assumed to be $75 \%$ of initial capital cost. The converters are assumed to be replaced in 15 years. The battery lifetime depends on how often and how heavily they are cycled. In the case of this analysis, a review of the model output files showed battery replacement intervals generally range from 11 to 15 years. 
Table 8-1: Converter and Battery Cost Curves. Source: conversations with installers, Vandermeer, J., Mueller-Stoffels, M., and Whitney, E. An Alaska Case Study: Energy Storage Technologies. JRSE, submitted.

\begin{tabular}{llll}
\hline Converter Size (kW) & Capital Cost $\mathbf{( \$ )}$ & Replacement Cost (\$) & O\&M Cost (\$/Year) \\
\hline 0 & $\$ 50,000$ & $\$ 37,500$ & $\$ 0$ \\
160 & $\$ 190,000$ & $\$ 142,000$ & $\$ 1,600$ \\
320 & $\$ 382,000$ & $\$ 178,500$ & $\$ 2,400$ \\
& & & \\
Battery Size (kWh) & Battery Cost $\mathbf{( \$ )}$ & Replacement Cost $\mathbf{( \$ )}$ & O\&M Cost (\$/Year) \\
0 & $\$ 50,000$ & $\$ 37,500$ & $\$ 0$ \\
200 & $\$ 190,000$ & $\$ 142,000$ & $\$ 4,000$ \\
400 & $\$ 382,000$ & $\$ 178,500$ & $\$ 6,000$ \\
\hline
\end{tabular}




\subsection{System Modeling}

Modeling of the Chefornak system was primarily conducted using the HOMER ${ }^{40}$ software package. HOMER is a commercially available micro-grid simulation and optimization software package.

On the simulation side, HOMER calculates the energy balance for every time step (an hour, for this analysis) for an entire year. The load must be met from some combination of grid purchases, on-site generation, or discharge from storage. Users have the option to allow some percentage of the load to be unmet. The technology modules in HOMER are based on empirical performance and cost data entered by the user. HOMER focuses on tracking energy flows and losses. It does not model items such as electrical system stability or transient effects.

When optimizing, HOMER finds the optimal component sizes and dispatch strategy subject to resource, operating, and goal constraints. The objective function is to minimize the NPC of the energy system.

The user may select from two available optimization methods. The first method is the HOMER proprietary optimizer. A drawback of this option is that it does not optimize the electric thermal stove capacity, requiring the user to specify this value. Since the electric thermal stove capacity is an important consideration for this particular study, this analysis used the second, "Search Space” method.

Under the Search Space method, the user enters the value(s) to simulate for each decision variable and HOMER will simulate every combination. This method has the benefit of being very transparent, but it depends on user judgment to ensure the defined search space includes the optimum configuration. Table 9-1 lists the decision variables in this analysis.

Table 9-1: Analysis Decision Variables

\begin{tabular}{l}
\hline \multicolumn{1}{c}{ Decision Variables } \\
\hline Wind turbines (\# of turbines, fixed size, $100 \mathrm{~kW})$ \\
PV capacity $(\mathrm{kW})$ \\
Converter capacity $(\mathrm{kW})$ \\
Battery storage capacity $(\mathrm{kWh})$ \\
Electric thermal stove capacity $(\mathrm{kW})$ \\
\hline
\end{tabular}

Power plants in remote Alaska communities generally have multiple diesel generators. For reliability and redundancy, these plants generally have at least two diesel generators sized to meet the peak load. Most plants also have one (or more) smaller diesel generators to allow for more cost-effective electricity generation when the loads are lower. In this type of analysis, the diesel generator sizes are often decision variables. There is a tradeoff between keeping in place the current generators at zero capital cost and incurring the upfront capital cost to purchase better-sized generators which will incur lower operating costs. For this analysis, it was determined that the existing generators are reasonably well sized, and there was no compelling economic reason to replace them. This has the advantage of somewhat simplifying the analysis. An analysis conducted to test this assumption verifies that there is negligible change in cost between fixing the small diesel generator at $179 \mathrm{~kW}$ and replacing it with a different generator size. The results are given in Chapter 10. In practice, as generators are replaced (e.g., due to wearing out), the size

\footnotetext{
${ }^{40}$ http://www.homerenergy.com/.
} 
of the replacement generator will be determined in part by the current and anticipated consumption at that time.

To minimize excessive diesel generator cycling, a 2-hour minimum run time requirement was imposed. This mean that once a diesel generator is dispatched, it is required to run for a minimum of 2 hours.

To better understand how system performance and economics change as the number of wind turbines changes, a series of model runs were conducted. For each run, the number of turbines was fixed. Runs were conducted with the number of turbines ranging from zero to 16.

For this analysis, the number of wind turbines drives the rest of the design. This is due in part because, in this analysis, the number of wind turbines is the "chunkiest" decision variable. Adding a wind turbine changes the capital cost by $\sim \$ 600,000$. In contrast, increasing the batter storage capacity by $100 \mathrm{kWh}$ increases the capital cost by $\$ 70,000$.

The analysis included sensitivity studies examining the effect of differing discount rates and the effect of energy efficiency. The sensitivity values are summarized in Table 9-2. An optimal system was determined for each combination of sensitivity cases. These combinations are enumerated in Table 9-3.

Table 9-2: Analysis Sensitivity Cases

\begin{tabular}{ll}
\hline \multicolumn{1}{c}{ Sensitivity Case } & \multicolumn{1}{c}{ Values } \\
\hline Nominal discount rate & $4 \%$ (low), 7\% (high) \\
EE & "No-EE", \\
& "With EE" \\
& $\bullet \quad$ Reduce thermal load by 25\% \\
& $\bullet \quad$ Reduce electrical load by 5\% \\
& $\bullet \quad$ Add \$2.25 million system capital cost \\
& to account for EE implementation cost \\
\hline
\end{tabular}

Table 9-3: Analysis Sensitivity Cases

\begin{tabular}{ll}
\hline Low discount rate & High discount rate \\
No EE & No EE \\
\hline Low discount rate & High discount rate \\
With EE & With EE \\
& \\
\hline
\end{tabular}




\subsection{Modeling Results}

This chapter summarizes the modeling results. In an effort to provide additional insight, the results are generally explained by showing a given metric, such as NPC, as a function of the number of wind turbines.

As modeled, each wind turbine produces slightly more than $400,000 \mathrm{kWh}$ per year. This is equal to $22 \%$ of the community's electrical consumption.

Note that while considered, PV was not part of any lowest-NPC system.

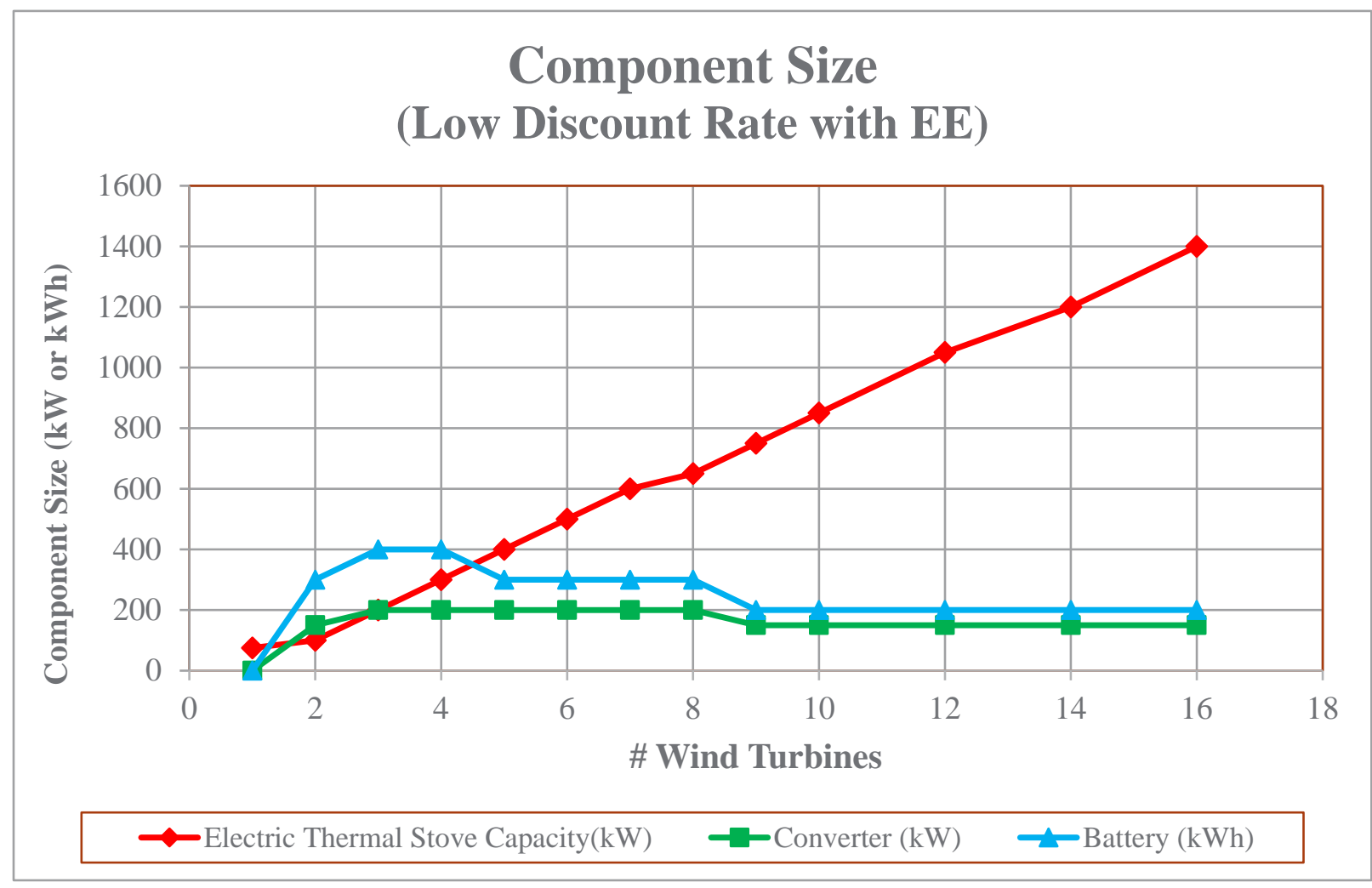

Figure 10-1: Component size versus number of wind turbines

\subsection{Component Sizes}

Figure 10-1 shows the battery storage size, converter rating, and electric thermal stove capacity as a function of the number of wind turbines in the system. Note that the respective component sizes are for the lowest Life Cycle Cost (LLC) system with the given number of wind turbines. The figure shows the sizes for the specific sensitivity case with the low discount rate and with EE implementation. The component sizes under the other sensitivity conditions are very similar. As shown in Figure 10-1, the battery storage capacity and the converter rating stay generally constant even as the number of turbines increases. This indicates that the real value of the storage system (batteries + converter) is in providing spinning reserve to allow dispatch of a smaller diesel or, when the wind turbine (or other RE technology) is generating, to allow diesel-off operation. The storage system provides energy during lulls in the RE production or spikes in the load. If the energy shortfall continues, the storage system covers the net load until a diesel generator can be dispatched. Throughout the analysis, the actual amount of energy cycling 
through the batteries is small. Once the storage system is large enough to provide spinning reserve and short-term storage, it is more economical to use excess wind energy (beyond what is needed to meet the current electrical load) to displace heating oil (Figure 10-1). In other words, the major purpose of the storage system is to allow for diesel-off operation when there is wind energy.

In contrast to the battery storage capacity and converter capacity, the electric thermal stove capacity increases as the number of wind turbines increases. With one wind turbine, the lowest-cost system includes a small quantity of electric thermal stove capacity ( $25 \mathrm{~kW}$ or four stoves), although having no stoves makes practically no difference in the economics. With two or more wind turbines, there is often sufficient excess wind energy (above what is needed to meet the electrical load within a given time step) to justify adding a significant number of electric thermal stoves.

\subsection{Fuel Consumption}

Figure 10-2 shows fuel consumption versus number of wind turbines. The red lines show diesel fuel (for power generation) consumption, the green lines show heating oil consumption, and the blue lines show total fuel consumption. Solid lines and dashed lines show consumption for the cases without and with EE, respectively. The results are for the low discount rate scenarios. The results for the corresponding high discount rate scenarios are nearly identical. Once the number of wind turbines is specified, the sizes of the remaining components, (battery bank, converter, etc.) tend to be the same or nearly so for both discount rates. Since the component sizes are the same or nearly so for both discount rates, the technical performance metrics, such as annual fuel consumption and diesel run time, tend to be the same or similar as well.

As expected, total fuel consumption decreases with each additional wind turbine. The graph shows the decreasing marginal utility of each succeeding wind turbine. The first two turbines reduce total fuel consumption by 45,000 gallons (case with EE). Going from 14 to 16 turbines only reduces total fuel consumption by 15,000 gallons (case with EE). Perhaps counter-intuitively, heating oil consumption actually increases with the first two turbines (case with EE). Most of the energy generated by these initial two wind turbines serves the electrical load, resulting in a decrease in both generator production and the quantity of recovered heat. This results in an increase in heating oil use, even though total fuel consumption is reduced.

After the initial two wind turbines, an increasing proportion of the energy from additional wind turbines goes to serve the thermal load, resulting in decreased heating oil use. Diesel fuel (for power generation) declines significantly with the first four to five wind turbines. After the fifth wind turbine, additional wind turbines do little to further reduce fuel consumption for power generation. Total fuel consumption decreases the most with the initial four to five wind turbines. More fuel is required to create a kilowatthour of electricity than to create a kilowatt-hour of heat. Thus, wind turbine energy serving an electrical load leads to a greater fuel reduction than the same amount of wind energy serving a thermal load. Because they mostly serve the electrical load, the initial three to four wind turbines each lead to a sharper drop in total fuel consumption than do additional wind turbines that mostly serve the thermal load.

Figure 10-2 also shows the effect of EE. Implementation of the EE measures alone, with a capital cost of $\$ 2.25$ million, reduces fuel consumption by almost 73,000 gallons/year. Achieving the same reduction with RE alone requires a system with four wind turbines with an initial capital cost of \$3.45 million.

Another way to examine the value of EE is to study what is needed to achieve a $50 \%$ reduction in fuel consumption. The "base case" fuel consumption (zero wind turbines and no EE) is 373,000 gallons/year. Without EE, a system with 14 wind turbines (requiring a capital investment of \$14 million) is needed to 
reduce overall fuel consumption by 50\%. With the assumed EE measures, a system with only seven turbines (with a capital cost of $\$ 7.5$ million, for both the RE and the EE) is required to achieve the same fuel reduction.

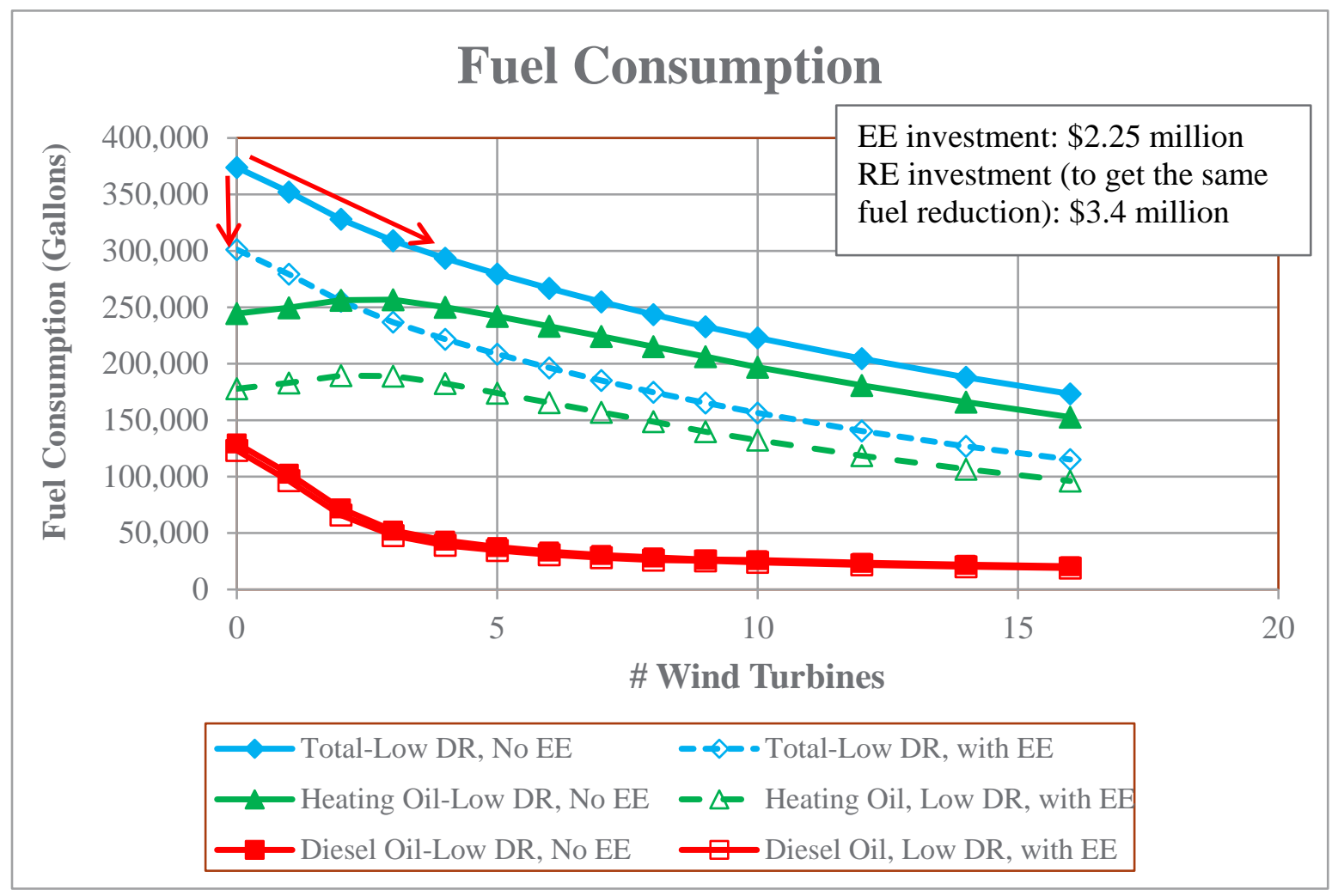

Figure 10-2: Fuel consumption versus number of wind turbines

\subsection{Diesel Run Time}

Figure 10-3 shows diesel run time as a function of the number of wind turbines. The sensitivity case shown is for the low discount rate (4\% nominal) and with EE. The results for the other sensitivity cases are very similar. With no wind turbines, the total diesel run time is just under 9,000 hours per year. In general, the most efficient way to dispatch a diesel generator is to dispatch the smallest unit that can meet the load plus any spinning reserve requirements while keeping the number or starts and stops within reasonable levels. Assuming the presence of a diesel with a rated power larger than the peak load, the total diesel annual run time should be 8,760 hours per year. The model shows a total diesel run time of 8,796 hours per year. This is due to a couple of factors. Due to anticipated load growth, there are a few hours per year (in the model) where the load plus the spinning reserve requirement exceeds the capacity of the large diesel and so the model dispatches both diesels. In addition, as stated earlier, the analysis imposes a 2-hour minimum run time on the diesel generators. Occasionally, during the second hour after the small diesel generator is dispatched, the load increases to the point that it is necessary to dispatch the larger diesel generator while the small smaller diesel generator continues to run. What would likely happen in reality is that as the load grows, the current largest diesel generator would be replaced by a somewhat larger unit. As can be seen from the figure, with zero wind turbines, most of the time it is the larger diesel generator that is dispatched. 
The addition of the first wind turbine results in only a slight decrease in total diesel run time. More dramatically, with this initial wind turbine plus the storage system, now the small diesel mostly runs. Recall that the average load (assuming EE implementation) is $194 \mathrm{~kW}$ and the rated wind turbine power is $100 \mathrm{~kW}$. With only one wind turbine, there are only a few hours during which the wind turbine can meet the entire electrical load (thus the small reduction in total diesel run time). However, there are many hours during which the wind turbine is serving enough of the electrical load to enable dispatch of the small diesel generator (rather than the large diesel generator).

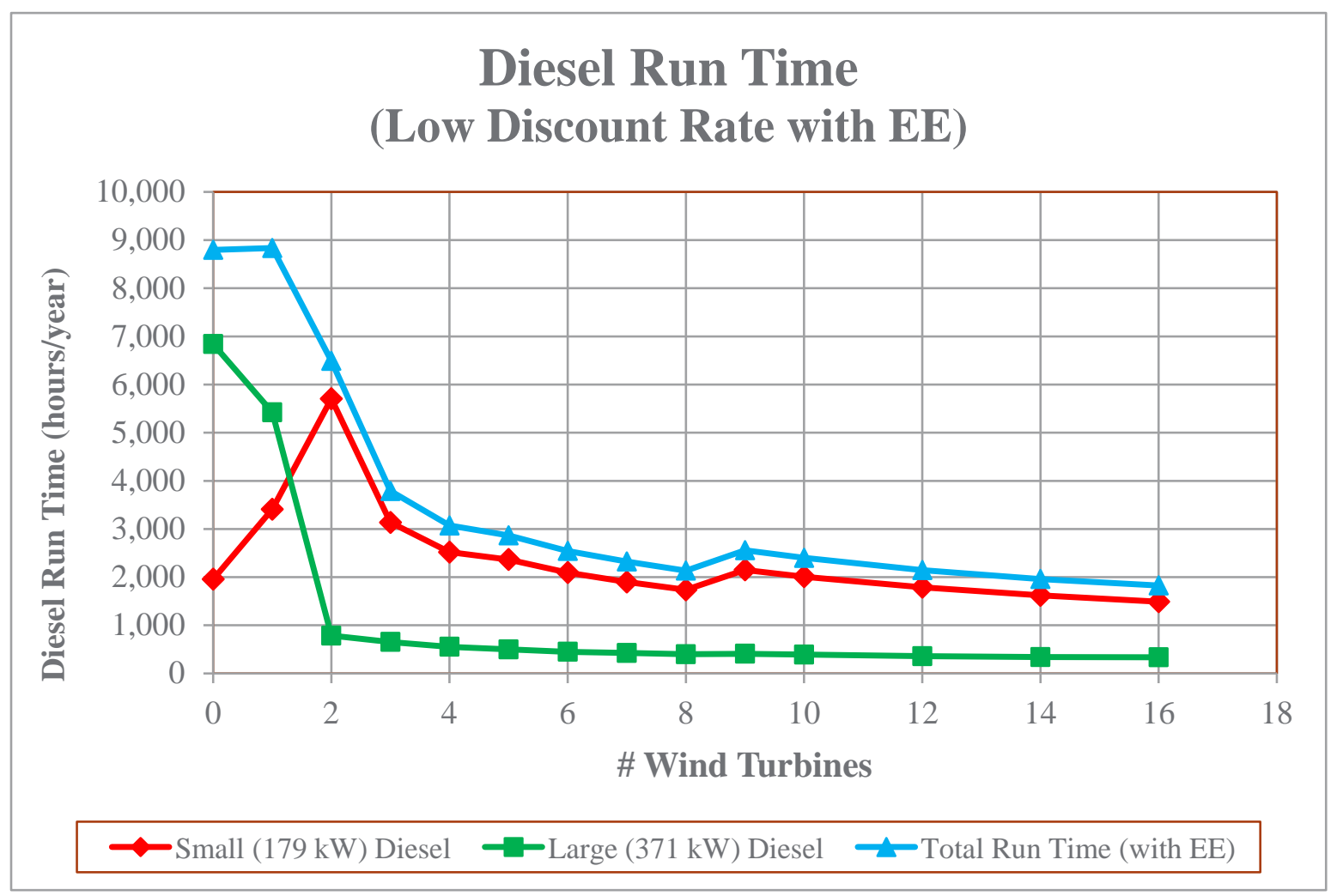

Figure 10-3: Diesel run time versus number of wind turbines

With the addition of a second turbine, the total wind turbine capacity (200 $\mathrm{kW})$ is roughly equal to the estimated average load ( $205 \mathrm{~kW})$. With the second wind turbine, there are more hours during which the wind turbines can meet the entire electrical load, resulting in an additional decrease in diesel run time. In this analysis, the third wind turbine is the tipping point, resulting in the greatest marginal reduction in diesel run time. The combined wind turbine capacity $(300 \mathrm{~kW})$ is significantly greater than the average load. Thus, even when producing at less than rated power, the turbines can often cover the whole electrical load (with the storage system providing the needed spinning reserve). The result is a dramatic decrease in total annual diesel run time from 6,600 hours to 3,800 hours. Beyond the fourth wind turbine, adding additional wind turbines does little to further reduce diesel run time. The energy from these turbines is going mostly to meet the thermal load. When going from eight to nine turbines, diesel run time actually increases slightly. This is most likely an artifact of the specific converter and battery sizes that were specified in the optimization search space. Going from eight wind turbines to nine, the lowest-cost configuration features a slightly smaller battery bank and converter. This results in a bit more wind energy going to meet the thermal load and a bit less going to meet the electrical load, with a corresponding bump up in diesel run time. Too much should not be made of this. As will be shown later (in Table 10-2), the cost curve around the optimal configuration is very shallow. For a configuration with 
a given number of wind turbines, there is a broad range of converter and battery storage sizes that result in practically identical NPCs.

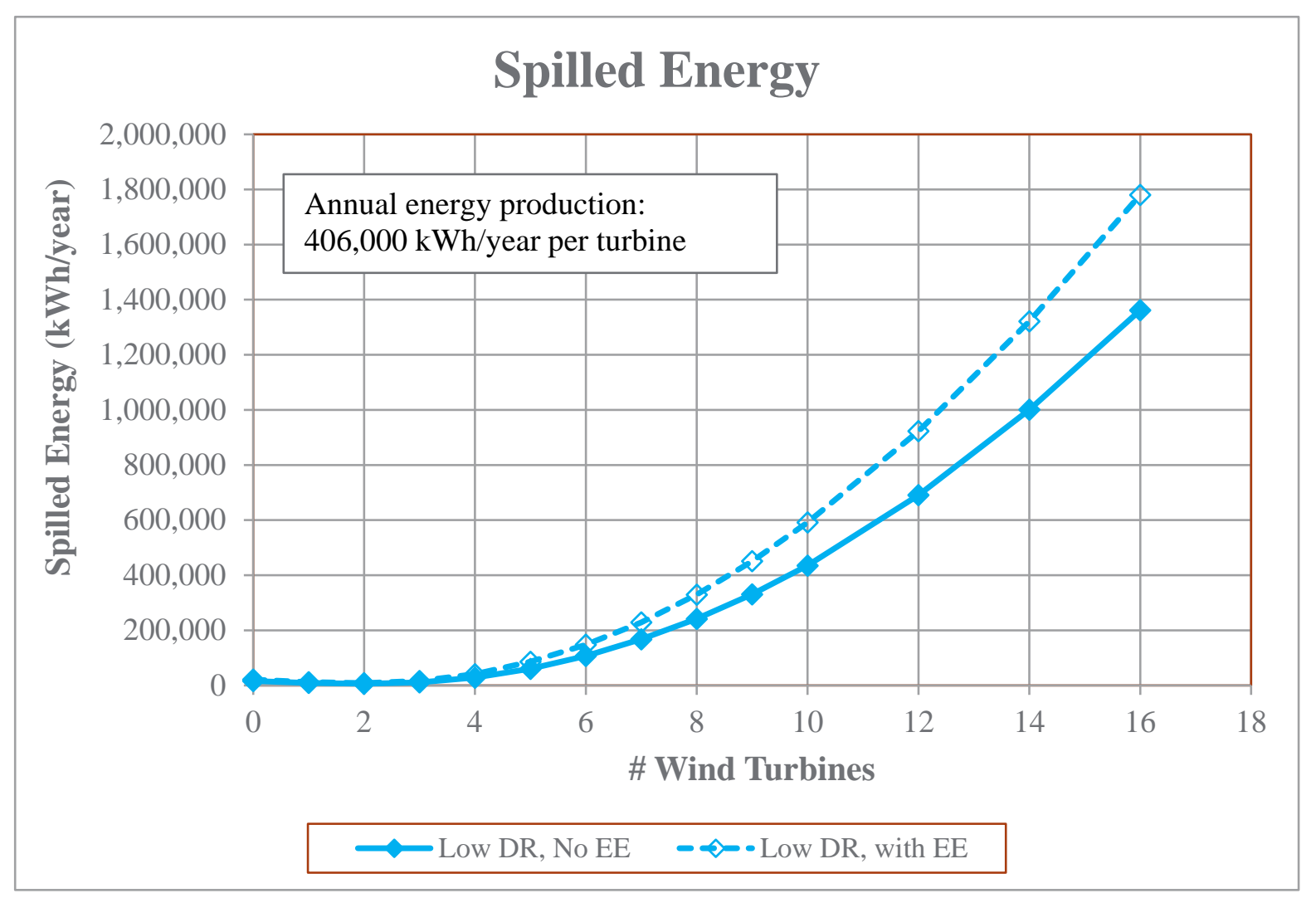

Figure 10-4: Spilled energy versus number of wind turbines

\subsection{Spilled Energy}

Figure 10-4 shows spilled energy versus number of wind turbines. Spilled energy is wasted energy that cannot be used for any purpose (i.e., to meet the electrical load, meet thermal load, or be stored). Sources of spilled energy can include wind energy in excess of what can be used to meet electrical or thermal loads or accommodated in the battery bank, recovered heat in excess of the thermal load, or excess energy from diesels that are running above the load due to minimum loading requirements. For purposes of this discussion, spilled energy includes energy that is produced but then must be disposed of and energy that could have been produced from renewable resources but wasn't because the generating source was curtailed. An example of this would be a wind turbine that is running at reduced (compared to what it could produce) power or turned off altogether because there is no use for the energy that would otherwise be produced.

Examination of spilled energy gives insight into the economics of adding additional renewable generating capacity. As shown in Figure 10-4, with the first few wind turbines there is little spilled energy. After the first five or six wind turbines, the quantity of spilled energy becomes significant. Each additional wind turbine has a greater proportion of its energy spilled than the preceding wind turbines. For example, for the with-EE case, increasing the number of wind turbines from eight to 10 increases the quantity of spilled energy by 260,000 kWh/year. Increasing the number of wind turbines from 14 to 16 increases the 
quantity of spilled energy by $460,000 \mathrm{kWh} /$ year. In the latter case, this is more than $50 \%$ of the energy produced by these turbines; thus a point is reached at which adding additional wind turbines is of little value because so much of the energy from the marginal turbine is spilled.

\subsection{Net Present Cost}

Figure 10-5 shows the NPC versus the number of wind turbines for all four sensitivity cases. The value of the NPC is for the lowest cost configuration with the given number of wind turbines. Low discount rate scenarios are shown in blue, high discount rate scenarios in red. Solid and dashed lines show scenarios with and without EE respectively. Black markers show the lowest NPC configuration for each sensitivity scenario.

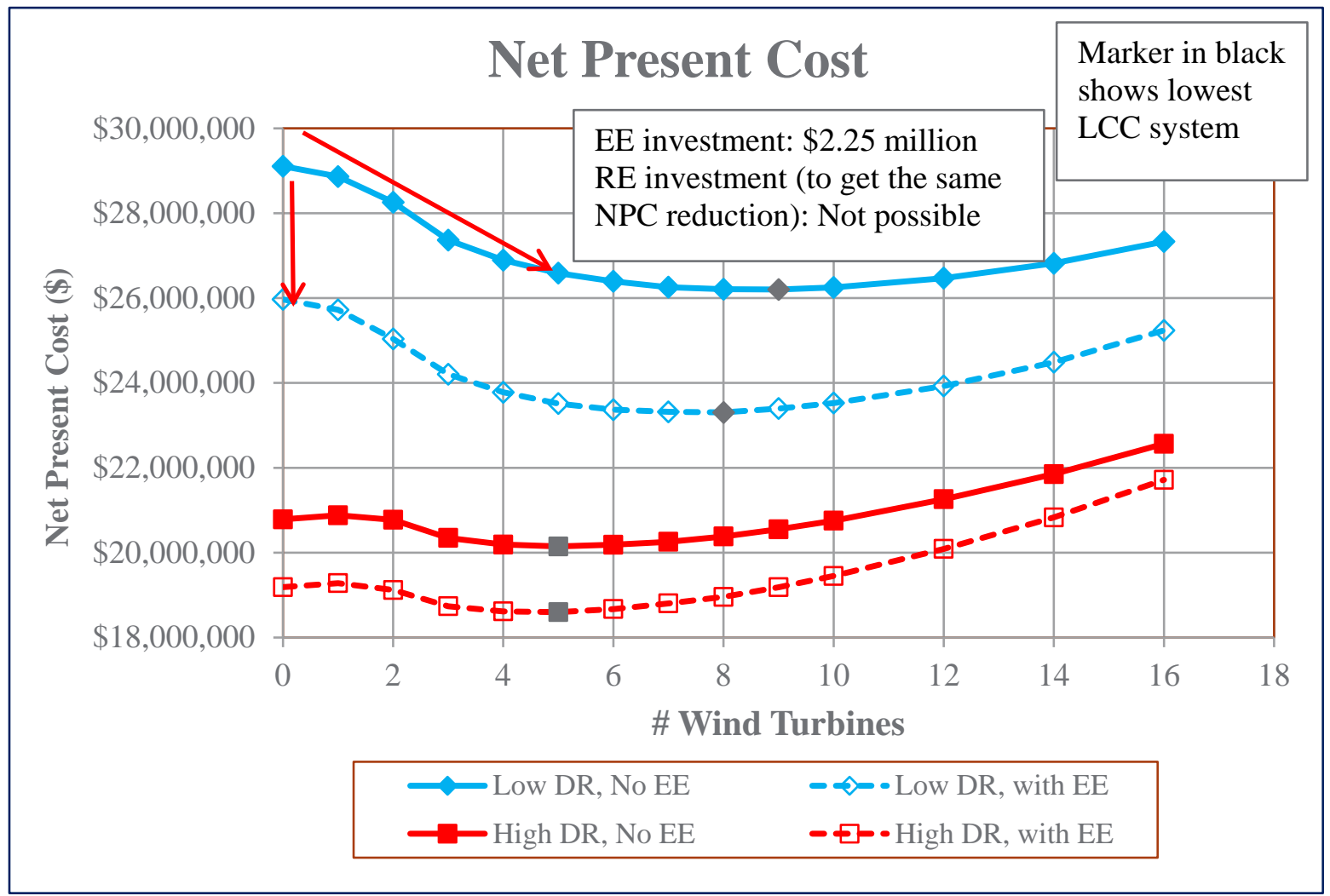

Figure 10-5: Net present cost versus number of wind turbines

The optimal number of wind turbines (from an NPC perspective) ranges from five (for the high discount rate sensitivity cases) to nine (for the sensitivity case of a low discount rate and no EE). With a low discount rate, the turbines reduce the 20-year NPC by \$3.3 million compared to the zero wind turbine case. With the higher discount rate, the corresponding reduction in NPC is about \$1 million. However, the cost curve is very shallow with respect to the number of wind turbines. Under the low discount rate, withEE sensitivity case, the number of turbines can vary from four to 11 with only a $2 \%$ change in overall life-cycle costs. What drives this shallow cost curve (with respect to number of wind turbines) is an (envisioned) cost-effective turbine combined with a very strong wind resource. The cost of energy from an additional wind turbine is not only less than the cost of energy of electricity from the diesel generator, it is comparable to the cost of energy of using heating oil for heat. Thus the wind turbines are costcompetitive with oil-fired stoves until a significant portion of the energy production of the additional wind turbines is spilled. 
The graph also shows the impact of EE. Implementing the EE measures alone costs $\$ 2.25$ million and reduces the NPC by $\$ 3.2$ million (for the low discount rate sensitivity). To get a similar reduction in NPC with $\mathrm{RE}$ alone requires an initial investment of $\$ 4$ million.

Comparing the zero wind turbine configurations with and without EE, implementing EE reduces the NPC by $\$ 3.2$ million (low discount rate) or by $\$ 1.6$ million (high discount rate). As wind turbines are added, the savings shrink somewhat, but even with 16 wind turbines the savings are \$2.1 million (low discount rate) and \$850,000 (high discount rate).

Combining RE with EE achieves the greatest savings. Compared to the base case (no RE and no EE), combining RE and EE saves up to \$6.5 million (low discount rate) and up to \$2.7 million (high discount rate). Under a low discount rate scenario, the lowest cost configuration with EE (eight wind turbines) also exceeds the goal of 50\% total fuel reduction. Without EE, achieving a 50\% total fuel reduction requires 14 wind turbines. With a high discount rate, the cost-optimal configuration of five wind turbines does not achieve a 50\% reduction in total fuel consumption. However, with EE, only two additional wind turbines are needed to achieve that goal. The increase in NPC (compared to the lowest NPC architecture) with the two additional wind turbines is marginal, only about $\$ 200,000$ (1\%).

Table 10-1 shows the details for selected configurations.

\section{Table 10-1: Details for Selected Configurations}

\begin{tabular}{|c|c|c|c|c|c|c|c|c|}
\hline \begin{tabular}{|l|} 
Note \\
\end{tabular} & 1 & 2 & 3 & 4 & 1 & 2 & 3 & 4 \\
\hline Nominal Discount Rate & 4 & 4 & 4 & 4 & 4 & 4 & 4 & 4 \\
\hline EE? & No & No & No & $\mathrm{No}$ & Yes & Yes & Yes & Yes \\
\hline \# Wind Turbines & 0 & 3 & 9 & 14 & 0 & 3 & 8 & 8 \\
\hline Battary Storage Capacity (kWh) & 0 & 400 & 300 & 200 & 0 & 400 & 300 & 300 \\
\hline Architecture/Converter (kW) & 0 & 200 & 200 & 150 & 0 & 200 & 200 & 200 \\
\hline Electric Thermal Stove Capacity (kW) & 0 & 200 & 750 & 1200 & 0 & 200 & 650 & 650 \\
\hline Dispatch Strategy & $\mathrm{LF}$ & $\mathrm{CC}$ & $\mathrm{CC}$ & $\mathrm{CC}$ & $\mathrm{LF}$ & $\mathrm{CC}$ & $\mathrm{CC}$ & $\mathrm{CC}$ \\
\hline Cost/NPC (\$) & $\$ 29,107,280$ & $\$ 27,366,890$ & $\$ 26,202,400$ & $\$ 26,819,290$ & $\$ 25,967,630$ & $\$ 24,205,820$ & $\$ 23,306,300$ & $\$ 23,306,300$ \\
\hline Cost/Initial capital (\$) & $\$ 0$ & $\$ 2,805,016$ & $\$ 6,427,062$ & $\$ 9,371,349$ & $\$ 2,250,000$ & $\$ 5,055,016$ & $\$ 8,067,054$ & $\$ 8,067,054$ \\
\hline System/Total Fuel (gal) & 373,397 & 308,597 & 232,533 & 187,779 & 300,787 & 236,584 & 174,507 & 174,507 \\
\hline Total Generator Run Time & 8,841 & 4,147 & 2,150 & 2,093 & 8,796 & 3,790 & 2,135 & 2,135 \\
\hline Nominal Discount Rate & 8 & 8 & 8 & 8 & 8 & 8 & 8 & 8 \\
\hline EE? & No & No & No & No & Yes & Yes & Yes & Yes \\
\hline \# Wind Turbines & 0 & 3 & 5 & 14 & 0 & 3 & 5 & 7 \\
\hline Battary Storage Capacity (kWh) & 0 & 300 & 300 & 200 & 0 & 400 & 300 & 200 \\
\hline Architecture/Converter (kW) & 0 & 200 & 200 & 150 & 0 & 200 & 200 & 150 \\
\hline Electric Thermal Stove Capacity (kW) & 0 & 200 & 400 & 1200 & 0 & 200 & 400 & 600 \\
\hline Dispatch Strategy & LF & $\mathrm{CC}$ & $\mathrm{CC}$ & $\mathrm{CC}$ & $\mathrm{LF}$ & $\mathrm{CC}$ & $\mathrm{CC}$ & $\mathrm{CC}$ \\
\hline Cost/NPC (\$) & $\$ 20,785,760$ & $\$ 20,348,480$ & $\$ 20,147,900$ & $\$ 21,850,970$ & $\$ 19,186,560$ & $\$ 18,737,680$ & $\$ 18,599,090$ & $\$ 18,803,690$ \\
\hline Cost/Initial capital (\$) & $\$ 0$ & $\$ 2,757,016$ & $\$ 4,012,033$ & $\$ 9,371,349$ & $\$ 2,250,000$ & $\$ 5,007,016$ & $\$ 6,262,033$ & $\$ 7,401,300$ \\
\hline System/Total Fuel (gal) & 373,397 & 308,724 & 279,240 & 187,779 & 300,219 & 236,729 & 208,310 & 185,048 \\
\hline Total Generator Run Time & 8,841 & 4,467 & 3,086 & 2,093 & 8,796 & 4,103 & 2,866 & 2,962 \\
\hline
\end{tabular}

Notes

1. All diesel (current situation) (included for reference)

2. Three wind turibnes (planned installation)

3. Configuration with lowest NPC

4. Configuration achieving $50 \%$ total fuel reduction 


\subsection{System Cost Breakdown}

Figure 10-6 shows the cost breakdown, by component, for the lowest NPC architecture assuming the low discount rate and EE implementation. The listed costs are annualized costs. The category labeled "Other" represents the EE implementation cost. A salvage credit is given to components that have useful remaining life at the end of the (in this case 20 years) analysis period. The salvage credit is equal to the proportion of remaining life in that component times the capital cost of that component. For example, for a component with a total lifetime of 25 years costing \$2 million with 5 years remaining at the end of the analysis period, the salvage credit would be $\$ 400,000$ ( $\$ 2$ million * 5 years / 25 years).

As the figure illustrates, the combined (electricity + thermal) energy costs are dominated by heating oil costs (the boiler cost), which are $\$ 740,000 /$ year. The remaining components with significant costs include the wind turbines (\$450,000/year), EE implementation (\$130,000/year), and the small (179-kW) diesel (\$120,000/year).

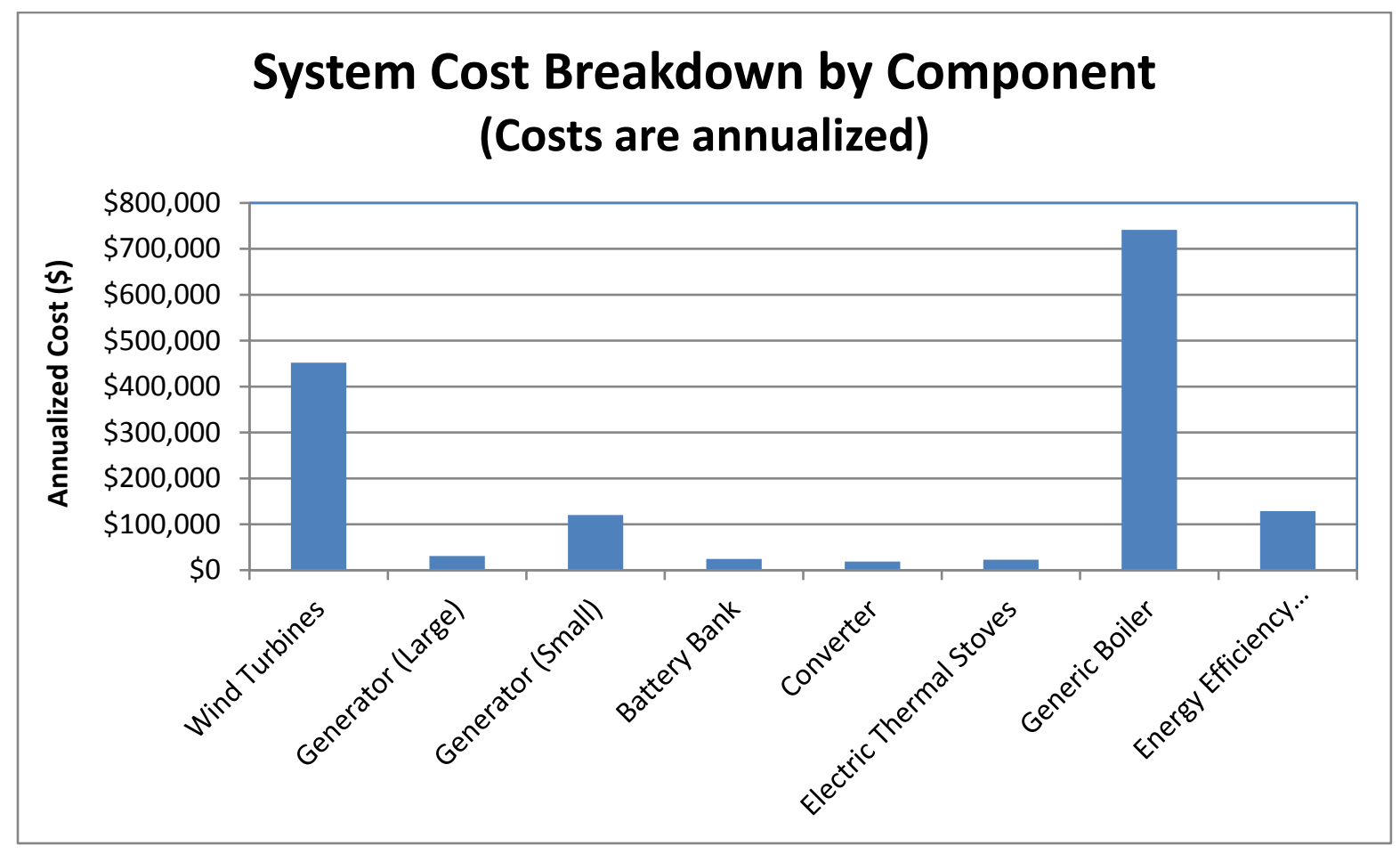

Figure 10-6: Cost breakdown for lowest net present cost configuration (8 Wind Turbines, Low Discount Rate, Energy Efficiency Implementation) . Listed costs are annualized.

\subsection{Results: Miscellaneous Topics}

This subsection addresses several miscellaneous issues and topics relating to the analysis results.

\subsubsection{Shallowness of the Cost Curve}

Table 10-2 shows how the NPC varies with changes from the (cost) optimal configuration. The table shows the percent increase in NPC, compared to the cost-optimal configuration, for different converter and battery bank sizes (keeping the number of wind turbines and electric thermal stove capacity constant). As can be seen from the table, as the converter size ranges from $100 \mathrm{~kW}$ to $300 \mathrm{~kW}$ and the battery bank 
storage capacity ranges from $100 \mathrm{kWh}$ to $800 \mathrm{kWh}$, the overall system NPC increases by no more than $3 \%$ compared to the cost-optimal system. Given all the uncertainties in the analysis, this is practically identical. The converter and battery bank sizes can vary somewhat from the optimal sizes with little effect on overall NPC.

Table 10-2: *Percent Change in Net Present Cost Versus Converter and Battery Bank Size

\begin{tabular}{|c|c|c|c|c|c|c|c|c|}
\hline & \multicolumn{7}{|c|}{ Battery Bank Size (kWh) } \\
\hline & & 100 & 200 & 300 & 400 & 500 & 600 & 800 \\
\hline \multirow{5}{*}{ 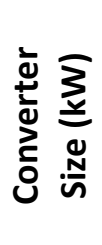 } & 100 & $1.1 \%$ & $0.6 \%$ & $1.0 \%$ & $1.4 \%$ & $1.7 \%$ & $2.1 \%$ & $2.9 \%$ \\
\hline & 150 & $1.4 \%$ & $0.1 \%$ & $0.1 \%$ & $0.4 \%$ & $0.7 \%$ & $1.1 \%$ & $1.8 \%$ \\
\hline & 200 & $1.6 \%$ & $0.3 \%$ & $0.0 \%$ & $0.2 \%$ & $0.5 \%$ & $0.8 \%$ & $1.5 \%$ \\
\hline & 250 & $1.7 \%$ & $0.5 \%$ & $0.2 \%$ & $0.4 \%$ & $0.7 \%$ & $1.0 \%$ & $1.6 \%$ \\
\hline & 300 & $1.9 \%$ & $0.6 \%$ & $0.4 \%$ & $0.7 \%$ & $0.9 \%$ & $1.2 \%$ & $1.8 \%$ \\
\hline
\end{tabular}

* Data are for the "Low DR-with EE" case with eight wind turbines.

\subsubsection{Diesel Generator Sizing}

To check the assumption that the current diesel generators are relatively well-sized, an analysis was conducted (assuming a low discount rate and with EE) fixing the number of wind turbines at eight and allowing the size of the small diesel generator to vary in 25-kW increments between $100 \mathrm{~kW}$ and $250 \mathrm{~kW}$. The resulting lowest-NPC configuration has a small generator rating of $225 \mathrm{~kW}$ and an NPC of $\$ 23,408,630$. This is practically the same as the $\$ 23,362,640$ NPC of the configuration using the existing 179-kW diesel generator.

\subsubsection{Sensitivity Analysis on PV Capital Costs}

After completion of the main part of the analysis, the team received information that the capital costs of recent PV installations in Alaska are lower than the costs assumed in this analysis. This motivated a further analysis to determine whether these lower costs would materially change the results. The team conducted a sensitivity analysis on PV capital costs for the case involving eight wind turbines, EE implementation, and the low discount rate. Results are shown in Table 10-3. As can be seen from Table 10-3, PV is not selected as part of the lowest-NPC system until PV capital costs (specifically panels, racking, and installation) fall below $\$ 2,000 / \mathrm{kW}$. This is still significantly below current costs in remote Alaska. Thus, the results presented earlier in this chapter remain unchanged. 
Table 10-3: *System Configuration Versus PV Capital Cost

\begin{tabular}{|c|c|c|c|c|c|}
\hline $\begin{array}{l}\text { PV Capital } \\
\text { Cost } \\
\left(\$ / \mathrm{kW}_{\mathrm{DC}}\right)\end{array}$ & $\begin{array}{l}\text { PV Capacity } \\
\left(k W_{D C}\right)\end{array}$ & $\begin{array}{l}\text { Battery } \\
\text { Bank } \\
\text { Capacity } \\
\text { (kWh) }\end{array}$ & $\begin{array}{l}\text { Converter } \\
\text { Capacity } \\
\text { (kW) }\end{array}$ & $\begin{array}{l}\text { Thermal } \\
\text { Electric } \\
\text { Stove } \\
\text { Capacity } \\
\text { (kW) }\end{array}$ & NPC (\$) \\
\hline$\$ 5,000$ & & 300 & 200 & 650 & $\$ 23,306,300$ \\
\hline$\$ 4,000$ & & 300 & 200 & 650 & $\$ 23,306,300$ \\
\hline$\$ 3,000$ & & 300 & 200 & 650 & $\$ 23,306,300$ \\
\hline$\$ 2,000$ & & 300 & 200 & 650 & $\$ 23,306,300$ \\
\hline$\$ 1,500$ & 100 & 300 & 200 & 650 & $\$ 23,304,390$ \\
\hline$\$ 1,000$ & 150 & 300 & 200 & 650 & $\$ 23,259,810$ \\
\hline
\end{tabular}

* Data are for the "Low DR-with EE" case with eight wind turbines. 


\subsection{Conclusions and Future Work}

\subsection{Conclusions (Specific to Chefornak)}

Based on the assumptions described earlier in this report, Table 11-1 and Table 11-2 show the recommended (based on lowest NPC) system configurations for both low and high discount rate scenarios. In all cases, the RE retrofits should be paired with EE upgrades. One important item to note is that the cost curve in the vicinity of the optimum is quite shallow with respect to the number of wind turbines, converter capacity, and battery capacity; thus the component number/size can vary moderately from the values shown in the tables with little change in NPC.

This flatness of the cost curve means there is flexibility to tailor a configuration to accommodate considerations other than NPC. For example, concerns about wind turbine technology risk or limited available capital funds would lead to a configuration with fewer wind turbines. A belief that fuel prices will be higher than assumed in the analysis may lead to a configuration with more wind turbines.

Currently there are plans to install three F24 wind turbines in Chefornak within the next year. The analysis indicates that, depending on the discount, the installation should include an additional two to seven wind turbines, roughly $300 \mathrm{kWh}$ of battery storage, roughly $200 \mathrm{~kW}$ of converter capacity, electric thermal stove capacity matched to the wind turbine capacity, and the integration and controls needed to allow for diesel-off operation. The installation of this equipment should be combined with aggressive EE implementation. However, a retrofit involving three turbines provides much of the benefits of a "lowest NPC” RE retrofit. In combination with an appropriate size converter and battery bank, three turbines should save about 240,000 liters of fuel (17\%) and reduce diesel run time by more than $50 \%$, resulting in a reduction in NPC of \$2.8 million (low discount rate) / \$1 million (high discount rate). Implementing the assumed EE measures would further reduce fuel consumption by another 270,000 L and reduce the NPC by another $\$ 4$ million (low discount rate) $\$ 2$ million (high discount rate).

Table 11-1: Recommended System Configuration (Low Discount Rate Case with Energy Efficiency)

\begin{tabular}{lrl}
\hline \multicolumn{1}{c}{ Component } & \multicolumn{1}{c}{ Value } & \multicolumn{1}{c}{ Note } \\
\hline $\begin{array}{l}\text { Large diesel size (kW) } \\
\text { Small diesel size (kW) }\end{array}$ & $371 \mathrm{~kW}$ & Keep current diesel generator \\
\# wind turbines & $179 \mathrm{~kW}$ & $\begin{array}{l}\text { Keep current diesel generator } \\
\text { (Frontier 24) }\end{array}$ \\
$\begin{array}{l}\text { PV capacity (kW) } \\
\text { Converter size (kW) }\end{array}$ & 8 & $\begin{array}{l}\text { \# of turbine can range from } 5 \text { to } 10 \text { with little } \\
\text { change in cost }\end{array}$ \\
$\begin{array}{ll}\text { Battery bank size (kWh) } \\
\text { Electric thermal stove } \\
\text { capacity (kW) }\end{array}$ & 0 & $\begin{array}{l}\text { Capacity can range from } 150 \mathrm{~kW} \text { to } 250 \mathrm{~kW} \text { with } \\
\text { little change in cost }\end{array}$ \\
\hline
\end{tabular}


Table 11-2: Recommended System Configuration (High Discount Rate Case with Energy Efficiency)

\begin{tabular}{|c|c|c|}
\hline Component & Value & Note \\
\hline Large diesel size (kW) & $371 \mathrm{~kW}$ & Keep current diesel generator \\
\hline Small diesel size $(\mathbf{k W})$ & $179 \mathrm{~kW}$ & Keep current diesel generator \\
\hline $\begin{array}{l}\text { \# wind turbines } \\
\text { (Frontier 24) }\end{array}$ & 5 & $\begin{array}{l}\text { \# of turbines can range from } 3 \text { to } 7 \text { with little } \\
\text { change in cost }\end{array}$ \\
\hline PV capacity (kWDC) & 0 & \\
\hline Converter size (kW) & $200 \mathrm{~kW}$ & $\begin{array}{l}\text { Capacity can range from } 150 \mathrm{~kW} \text { to } 250 \mathrm{~kW} \text { with } \\
\text { little change in cost }\end{array}$ \\
\hline Battery bank size (kWh) & $300 \mathrm{kWh}$ & $\begin{array}{l}\text { Capacity can range from } 100 \mathrm{kWh} \text { to } 600 \mathrm{kWh} \\
\text { with little change in cost }\end{array}$ \\
\hline $\begin{array}{l}\text { Electric thermal stove } \\
\text { capacity }(\mathrm{kW})\end{array}$ & $400 \mathrm{~kW}$ & Probably a low estimate \\
\hline
\end{tabular}

Achieving a 50\% reduction in electricity and heat fuel consumption requires the implementation of EE measures (assumed to be a $5 \%$ reduction in end use electricity and a $25 \%$ reduction in thermal use), seven wind turbines, short-term battery storage, and the extensive replacement of largely fuel-based thermal energy with locally produced wind energy. This analysis excludes consideration of transportation fuel.

EE is generally more cost effective than RE retrofits (as shown in Figure 10-5). RE retrofits should be paired with EE implementation. Without EE, it is difficult to simultaneously reduce fuel consumption by $50 \%$ and reduce costs. With EE, a configuration achieving a 50\% reduction in total fuel use is the lowestcost solution (low discount rate) or is close to the lowest-cost solution (high discount rate).

Because of the excellent wind resource at Chefornak, wind-produced electricity can be provided at roughly the same cost as fuel oil-produced heat, allowing energy from wind to effectively displace heating oil. The electric thermal stove capacity generally scales with the turbine capacity. As the number of turbines increases, an increasing proportion of the wind turbine energy goes toward meeting the thermal load.

The converter size does not scale with the number of turbines. Since the wind turbines in this case are connected directly to the AC bus, the converter needs only to be large enough to facilitate needed energy draws to/from the battery.

Battery storage does not scale with increasing number of turbines. The economically optimal battery size is roughly an hour of autonomy (based on the average load). The main value of the battery bank and converter is that they allow for the safe dispatch of a smaller diesel, or for diesel-off operation altogether, by providing spinning reserve to cover short-term lulls in the wind resource or spikes in electrical demand. Another driver of this non-scaling of the battery and converter is the existence of (inexpensive) thermal electric stoves that allow for the productive use of excess (above what is needed to meet the electrical load at the moment) wind energy. Rather than oversizing the battery storage to capture additional excess wind energy, it is less expensive to use the excess wind energy to displace heating oil.

The model indicates that cycle charging is the economically preferred dispatch strategy. For a five-turbine configuration, load following increases the NPC by roughly $1 \%$ to $2 \%$ compared to cycle charging. Under a load-following strategy, when a diesel is dispatched, it is run at the net load (the load minus any current renewable energy production). With a cycle-charging strategy, when a diesel is dispatched, it charges the 
battery in addition to meeting the net load. Depending on the circumstances, one strategy may be significantly more cost effective than the other.

\subsection{Conclusions (General)}

\subsubsection{Caveats/Limitations}

Generalizing the results of this analysis must be done with care. The analysis results are most generalizable to wind-diesel systems in communities with a good wind resource and a large thermal load. The results may not apply to the integration of other renewable energy technologies.

References to "total energy” or "overall energy” include electrical and thermal loads but not transportation loads.

\subsubsection{General Design Lessons}

With a good wind resource and cost-effective wind turbines, achieving a 50\% reduction in imported fuel may be economically feasible with a combination of RE retrofits and EE. Achieving $50 \%$ imported fuel reduction with $\mathrm{RE}$ alone is generally economically marginal at best.

EE is key to achieving greater imported fuel reduction. The data indicate that implementation of costeffective EE measures alone (mostly weatherization in the case of remote Alaska communities) can reduce imported fuel by $20 \%$ or more.

Generating a kilowatt-hour of electricity requires more fuel than generating a kilowatt-hour of heat. Thus, energy from electricity-producing RE technologies, such as wind or PV, is more cost competitive versus diesel-generated electricity than versus heating-oil-generated heat. This also partially explains why the initial wind turbines displace more fuel than do later wind turbines.

The main value of storage is to allow for more extended diesel-off operation by covering short-term lulls in wind energy production. This function requires only a modest amount of storage (assumed to be "generic" Lithium-ion batteries) and converter capacity. The required battery bank should be sized to meet roughly an hour of average load. In practice, the storage capacity could range from 0.5 to $2.0+$ hours with little change in overall system cost. Unlike for very small systems (e.g., a single house) where the storage supplies the load when there is no RE production, the value of storage for community-size systems is to allow diesel-off operation when there is RE production.

Battery cell geometry can be adjusted to maximize discharge capacity (kW) or energy storage (kWh). Further analysis to optimize the ratio of discharge capacity to storage could result in further savings by allowing for the use of a smaller battery bank.

The converter rated power is somewhere between the average and the peak load (for situations in which the turbine is connected to the AC bus).

Water and space heating are an excellent use for excess wind energy that would otherwise be spilled and may allow for larger renewable energy systems and better economics. This is what allows for the use of modestly sized converters and battery banks. Economically, use of excess wind energy for heat is needed to go beyond low-contribution wind systems. 
It is important to remember that the above discussion refers to the total energy consumption (electricity and heat) of a community with a large thermal load. Looking at just the electrical piece, the relative reduction in fuel consumption is much larger. Eight wind turbines in combination with EE reduce diesel fuel consumption (for electricity) by almost $80 \%$. 


\section{Appendix A}

\section{Analysis Inputs and Assumptions}




\begin{tabular}{|c|c|c|}
\hline Item & Value & Note \\
\hline Annual electric load (kWh) & $1,790,000$ & Average load: 205 kW \\
\hline Peak electric load (kW) & 360 & \\
\hline Annual thermal load $\left(\mathrm{kWh}_{\mathrm{th}}\right)$ & $8,596,000$ & Average load: 980 kWth \\
\hline Peak thermal load $\left(\mathrm{kW}_{\text {th }}\right)$ & 3,700 & \\
\hline Generator (both) capital cost (\$) & $\$ 0$ & Assume use of current generators \\
\hline Generator (179 kW) replacement cost (\$) & $\$ 73,600$ & \\
\hline Generator (371 kW) replacement cost (\$) & $\$ 152,000$ & \\
\hline Generator (179 kW) operating cost $(\$ / \mathrm{hr})$ & $\$ 15.64$ & \\
\hline Generator (371 kW) operating cost $(\$ / \mathrm{hr})$ & $\$ 16.80$ & \\
\hline Generator (179 kW) lifetime (operating hours) & 60,000 & \\
\hline Generator (371 kW) lifetime (operating hours) & 100,000 & \\
\hline $\begin{array}{l}\text { Generator (179 kW) no-load fuel consumption } \\
\text { (gal/hr) }\end{array}$ & $\begin{array}{r}0.95 \\
\text { gal/hour }\end{array}$ & \\
\hline $\begin{array}{l}\text { Generator (179 kW) marginal fuel } \\
\text { consumption }(\mathrm{gal} / \mathrm{kWh})\end{array}$ & $\begin{array}{r}0.063 \\
\mathrm{gal} / \mathrm{kWh}\end{array}$ & \\
\hline $\begin{array}{l}\text { Generator (371 kW) no-load fuel consumption } \\
\text { (gal/hr/kWr) }\end{array}$ & $\begin{array}{r}1.96 \\
\text { gal/hour }\end{array}$ & \\
\hline $\begin{array}{l}\text { Generator }(371 \mathrm{~kW}) \text { marginal fuel } \\
\text { consumption }(\mathrm{L} / \mathrm{kWh})\end{array}$ & $\begin{array}{r}0.063 \\
\text { gal/kWh }\end{array}$ & \\
\hline Generator (both) minimum load (\%) & $30 \%$ & \\
\hline Diesel fuel cost (\$/gal) & $\$ 4.50 /$ gal & $(\$ 1.19 / \mathrm{L})$ \\
\hline Heating oil cost (\$/gal) & $\$ 5.00 /$ gal & $(\$ 1.32 / \mathrm{L})$ \\
\hline Wind turbine (F24) capital cost (fixed) (\$) & $\$ 200,000$ & $\begin{array}{l}\text { Cost of controls to integrate wind } \\
\text { turbines and allow for diesel-off } \\
\text { operation }\end{array}$ \\
\hline $\begin{array}{l}\text { Wind turbine (F24) capital cost (marginal) } \\
\text { (\$/wind turbine) }\end{array}$ & $\$ 700,000$ & $\begin{array}{l}\text { Turbine 2: } \$ 665,000 \text { (5\% discount) } \\
\text { Turbine 3: } \$ 630,000 \text { (10\% discount) } \\
\text { Turbine 4: } \$ 595,000 \text { (15\% discount) } \\
\text { Turbine 5+: } \$ 560,000 \text { (20\% discount) }\end{array}$ \\
\hline Wind turbine replacement cost (\$/turbine) & $\$ 560,000$ & $\begin{array}{l}\text { Turbine 2: } \$ 532,000 \text { (5\% discount) } \\
\text { Turbine 3: } \$ 504,000 \text { (10\% discount) } \\
\text { Turbine 4: } \$ 476,000 \text { (15\% discount) }\end{array}$ \\
\hline
\end{tabular}




\begin{tabular}{|c|c|c|}
\hline Item & Value & Note \\
\hline & & Turbine 5+: \$448,000 (20\% discount) \\
\hline Wind turbine O\&M costs (\$/year/turbine) & $\$ 17,500$ & $\begin{array}{l}\text { Turbine 2: } \$ 16,625 \text { (5\% discount) } \\
\text { Turbine 3: } \$ 15,750 \text { (10\% discount) } \\
\text { Turbine 4: } \$ 14,875 \text { (15\% discount) } \\
\text { Turbine 5+: } \$ 14,000 \text { (20\% discount) }\end{array}$ \\
\hline Wind turbine lifetime (years) & 20 & \\
\hline Wind turbine hub height (m) & 50 & \\
\hline Average wind speed (m/s) & 7.27 & \\
\hline Wind speed reference height (m) & 29 & \\
\hline Wind speed shear factor & 0.15 & \\
\hline Photovoltaic capital cost $\left(\$ / \mathrm{kW}_{\mathrm{DC}}\right)$ & $\$ 5,000$ & \\
\hline Photovoltaic replacement cost $\left(\$ / \mathrm{kW}_{\mathrm{DC}}\right)$ & $\$ 4,000$ & \\
\hline Photovoltaic O\&M cost $\left(\$ /\right.$ year $\left./ \mathrm{kW}_{\mathrm{DC}}\right)$ & $\$ 10$ & \\
\hline Photovoltaic derating factor & $80 \%$ & $\begin{array}{l}\text { The PV output is multiplied by the } \\
\text { derating factor to account for real- } \\
\text { world loss factors. }\end{array}$ \\
\hline $\begin{array}{l}\text { Average global horizontal solar resource } \\
\left(\mathrm{kWh} / \mathrm{m}^{2} / \text { day }\right)\end{array}$ & 2.54 & \\
\hline Battery type & Lithium-ion & $\begin{array}{l}\text { Generic Lithium-ion } \\
\text { (detailed parameters are in the } \\
\text { HOMER model.) }\end{array}$ \\
\hline Battery round trip efficiency & See note & $\begin{array}{l}\text { Efficiency is not an explicit input but } \\
\text { rather is based on detailed model } \\
\text { inputs and varies depending on state of } \\
\text { charge and charge/discharge rate. For } \\
\text { the battery model selected, the } \\
\text { modeling results show an overall value } \\
\text { for round trip efficiency of } \sim 90 \% \text {. }\end{array}$ \\
\hline Battery capital cost (fixed) (\$) & $\$ 50,000$ & \\
\hline Battery capital cost (marginal) ( $\$ / \mathrm{kWh})$ & Varies & $\begin{array}{l}(0-200 \mathrm{kWh}): \$ 700 / \mathrm{kWh} \\
(>200 \mathrm{kWh}): \$ 480 / \mathrm{kWh}\end{array}$ \\
\hline Battery replacement cost (\$) & See note & $75 \%$ of CAPEX \\
\hline
\end{tabular}




\begin{tabular}{|c|c|c|}
\hline Item & Value & Note \\
\hline Battery O\&M cost ( $\$ / \mathrm{kWh}_{\text {storage capacity }} /$ year) & $\$ 20$ & \\
\hline Battery lifetime (years) & See note & Based on usage \\
\hline Battery minimum state of charge (\%) & $20 \%$ & \\
\hline Converter capital cost (fixed) (\$) & $\$ 50,000$ & \\
\hline Converter capital cost (marginal) $(\$ / \mathrm{kWh})$ & varies & $\begin{array}{l}(0-160 \mathrm{~kW}): \$ 875 / \mathrm{kW} \\
(>160 \mathrm{~kW}): \$ 600 / \mathrm{kW}\end{array}$ \\
\hline Converter replacement cost (\$) & See note & $75 \%$ of CAPEX \\
\hline Converter O\&M cost ( $\$ / \mathrm{kW} /$ year) & \$10/kW/year & \\
\hline Converter lifetime (years) & 15 & \\
\hline Electric thermal stove capital cost (fixed) (\$) & $\$ 10,000$ & \\
\hline $\begin{array}{l}\text { Electric thermal stove capital cost (marginal) } \\
(\$ / \mathrm{kW})\end{array}$ & $\$ 500$ & \\
\hline Electric thermal stove lifetime (years) & 20 & \\
\hline Inflation rate $(\%)$ & $1 \%$ & \\
\hline Discount rate (marginal) (\%) & $4 \%, 7 \%$ & $\rightarrow$ real discount rate: $3 \%$ and $7 \%$ \\
\hline EE (electrical) (reduction in consumption) & $0 \%, 5 \%$ & $\begin{array}{l}\text { Implementation cost: \$1.15 per annual } \\
\text { kWh saved }\end{array}$ \\
\hline EE (thermal) (reduction in consumption) & $0 \%, 25 \%$ & $\begin{array}{l}\text { Implementation cost: } \$ 1.00 \text { per annual } \\
\text { kWh saved }\end{array}$ \\
\hline
\end{tabular}





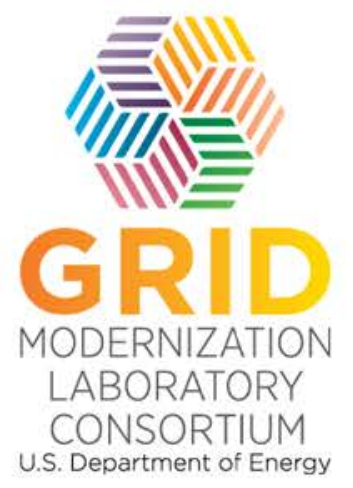

National Renewable Energy Laboratory 15013 Denver West Parkway

Golden, CO 80401 